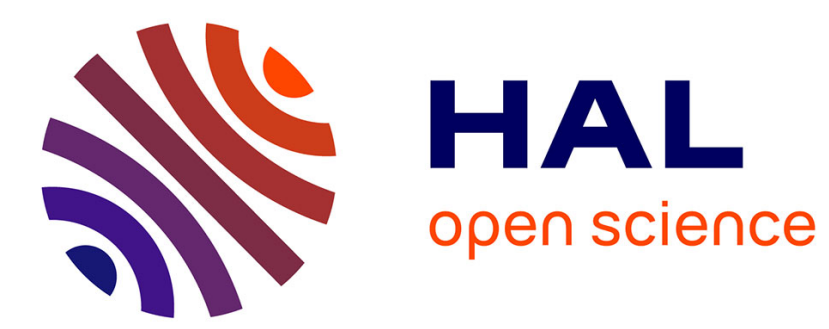

\title{
Les inscriptions de l'église de Saint-Savin-sur-Gartempe
}

Robert Favreau

\section{To cite this version:}

Robert Favreau. Les inscriptions de l'église de Saint-Savin-sur-Gartempe. Cahiers de Civilisation Médiévale, 1976, 19 (73), pp.9-37. 10.3406/ccmed.1976.2027 . halshs-03201987

\section{HAL Id: halshs-03201987 https://shs.hal.science/halshs-03201987}

Submitted on 19 Apr 2021

HAL is a multi-disciplinary open access archive for the deposit and dissemination of scientific research documents, whether they are published or not. The documents may come from teaching and research institutions in France or abroad, or from public or private research centers.
L'archive ouverte pluridisciplinaire HAL, est destinée au dépôt et à la diffusion de documents scientifiques de niveau recherche, publiés ou non, émanant des établissements d'enseignement et de recherche français ou étrangers, des laboratoires publics ou privés. 


\section{Les inscriptions de l'église de Saint-Savin-sur-Gartempe} Robert Favreau

Citer ce document / Cite this document :

Favreau Robert. Les inscriptions de l'église de Saint-Savin-sur-Gartempe. In: Cahiers de civilisation médiévale, 19e année $\left(n^{\circ} 73\right)$, Janvier-mars 1976. pp. 9-37;

doi : https://doi.org/10.3406/ccmed.1976.2027

https://www.persee.fr/doc/ccmed_0007-9731_1976_num_19_73_2027

Fichier pdf généré le 25/03/2019 


\section{Robert FAVREAU}

\section{Les inscriptions de l'église de Saint-Savin-sur-Gartempe}

L'église de Saint-Savin est connue de tous les archéologues et historiens de l'art. Pourtant il reste encore à étudier à son propos un dossier important, celui des inscriptions que l'on rencontre dans toutes les parties de la célèbre abbatiale : épitaphes d'abbés, inscriptions de consécration des autels du déambulatoire, du transept, du chœur, textes peints pour expliquer le programme de la crypte, du chœur, de la nef, de la tribune, du narthex, ensemble qui a si peu retenu l'attention qu'une partie notable en est encore inédite. Il manque également un historique de l'abbaye, pour lequel les sources d'archives sont à peu près inexistantes en raison de la destruction du chartrier de l'abbaye au xv1 ${ }^{\mathrm{e}} \mathrm{s}$., ce qui oblige à recourir essentiellement à des sources narratives et hagiographiques. Si un article récent a fait le point sur les monastères poitevins avant l'an mil, tout ce qui a été publié sur l'histoire de Saint-Savin au $\mathrm{XI}^{\mathrm{e}} \mathrm{s}$. repose encore sur les travaux des Bénédictins du $\mathrm{XvII}^{\mathrm{e}}$ et du XvIrre $\mathbf{s} .^{1}$. Il sera donc ici question à la fois d'épigraphie et d'histoire, l'une et l'autre étant intimement liées et complémentaires.

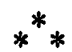

Les débuts de Saint-Savin sont fort incertains. Les restes des saints Savin et Cyprien, martyrs du ve $v^{\mathbf{s}}$, auraient été découverts, à la fin du viri ${ }^{\mathrm{e}}$ ou au début du $\mathrm{IX}^{\mathrm{e}} \mathrm{s}$., à Cerasus, Cerisier, lieu alors inhabité, sur le domaine d'un certain Baidilus, clerc palatin de la cour de Charlemagne, abbé de Marmoutier. Baidilus s'empressa de faire bâtir sur ses terres une église pour abriter les corps saints, ainsi que divers bâtiments où il installa des clercs ${ }^{2}$. Quant à Charlemagne, il ordonna de construire le castrum qui devait protéger le nouveau lieu de culte ${ }^{3}$. Louis, alors roi d'Aquitaine, donna l'élan décisif à cette fondation en la confiant à Benoît d'Aniane qui y établit vingt moines. Et très vite à ceux-ci se joignirent de nombreux frères ${ }^{4}$. Ce schéma repose sur des sources hagiographiques, mais aussi sur plusieurs chroniques générales ou locales. La fondation de Saint-Savin s'insérerait donc en un mouvement non négligeable de renouveau monastique dans la région : érection de l'abbaye de Charroux et établissement de l'abbaye de Nouaillé à la fin du virr ${ }^{\mathbf{e}} \mathbf{s}$., instauration de la règle d'Aix à Saint-Hilaire-le-Grand, appel à un religieux du Mont-Cassin et interventions renouvelées au début $\mathrm{du}_{\mathrm{Ix}}^{\mathrm{e}} \mathrm{s}$. pour restaurer la règle bénédictine à Saint-Maixent $\mathrm{t}^{5}$.

1. Un historique manuscrit de l'abbaye a êté donné par dom $\mathrm{Cl}$. EstrevNơ au XVII $\mathrm{s}$. dans Antiquitatum in dioecesi Pictaviensi benedictarum pars secunda (B.N., lat. 12756 , p. 40-89 et $435-450$ pour les probationes) et par dom L. FONTENEAU au XVM ${ }^{e}$ s. (Bibl. mun. Poitiers, t. IXXX, p. 415-471, 789-790). Pr. Mérrmé dans Notice sur les peintures de l'ćglise de Saint-Savin, Paris, 1845, p. 1938, et El. MaIllakd dans L'église de Saint-Savin-sur-Gartempe, Paris, 1926, p. I1-22, ont donné dans leurs études un chapitre historique préliminaire dont la partie médiévale repose essentiellement sur les travaux de dom Fonteneau. Irr. Coutasisals a retracé, en s'appuyant sur les meilleures sources, les deux premiers siccles de Saint-Savin, dans Les monasteres du Poitou avant l'an mil, "Revue Mabillon ", LIII, I963, p. I-2I.

2. Armon, Acta translationis s. Savini martyris, P.L., CXXVI, ro51-1053; dom RABORY, Histoire de Marmoutier et de ses prieurés, Paris, t. I, I910, p. 59-60. On peut observer que la commune d'Antigny s'avance jusqu'à la limite même de l'abbaye; fort probablement la paroisse de Saint-Savin a été établie par démembrement de la paroisse d'Antigny, centre le plus ancien de la région.

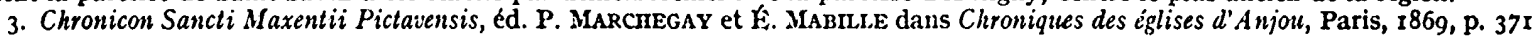

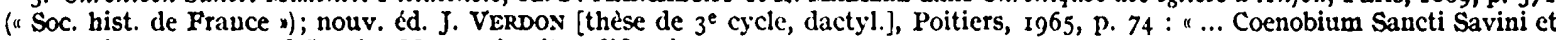
castrum in quo est, quod Carolus Magnus jussit aedificari $n$.

4. Ardon, Vita Benedicti Anianensis et Indensis, M.G.H., SS., XV/I, 1887, p. 214; Vita Hludowici imperatoris, éd. G.H. PERTz, M.G.H., SS., II, I 829, p. 616-617 : liste des abbayes d'Aquitaine que Iouis fonda ou auxquelles il apporta un soutien tres actif. L'abbaye de Saint-Savin fait partie des dix-huit monastères d'Aquitaine que le concile d'Aix de 817 déclara exempts de toutes obligations de service armé (Annales ordinis s. Benedicti..., éd. MaBrllon, Paris, t. II, 1704, p. 438).

5. Fr. Coutavsais, op. cit., p. 5-7. 
Ce renouveau monastique se poursuivit d'ailleurs jusqu'au milieu du $\mathrm{Ix}^{\mathrm{e}} \mathrm{s}$., et la jeune abbaye de Saint-Savin y joua un rôle de premier plan, sous l'impulsion de l'abbé Dodon, disciple et successeur de Benoit d'Aniane ${ }^{6}$. I.e tombeau de Dodon, enfoui dans l'église paroissiale de Saint-Savin, près du baptistère, fut trouvé au cours de fouilles, et un bénédictin du Xvin ${ }^{e}$ s., dom I.éonard Fonteneau, le vit, le mesura, et recopia l'inscription qui courait tout au long de la pierre:

IN HOC TUMULO REQUIESCIT SANCTAE MEMORIAE DOMNUS DODO ABBA, QUI MULTORUM MONACHORUM EXTITIT PATER, NAM HUJUS LOCI PATER ELECTLS, NON SOLUM HUNC LOCUM EDIFICIIS ET REBUS AMPI,IFICAVI'T, SED ETIAM QUINQUE A FUNDAMENTIS MONASTERIA CONSTRUXIT. IN PLURIBUS VERO ALIIS LOCIS IN OUIBUS REGULARIS ORDO DEFECERA'T SUO EXEMPLO MONASTICUM ORDINEM REFORMAVI'T. MIGRAVIT AUTEM A SECULO IIII IDUS JUNIAS, ANNO INCARNATIONIS DOMINI DCCCLIII, ETATIS VERO FERME XC. REXI'T AUTEM HUNC LOCUM NOBILITER ANNOS CIRCI'TER XXX.

" Ein ce tombeau repose le seigneur Dodon abbé, de sainte mémoire, qui de nombreux moines fut le père. Choisi comme père de ce lieu, non seulement il l'accrut par des constructions et des domaines, mais encore il construisit de fond en conble cinq autres monastères. Fin outre dans plusieurs autres couvents dans lesquels l'observance de la règle était déficiente, il rétablit par son exemple l'ordre monastique. Il quitta ce monde le 4 des ides de juin, l'an de l'incarnation du Seigneur 853, âgé de presque 9o ans. Il gouverna ce monastère magnifiquement pendant trente ans environ. "

Cette pierre fut malheureusement détruite vers I8I I, lorsqu'on procéda à la démolition de l'église paroissiale, et le premier élément du dossier épigraphique de Saint-Savin n'est plus constitué que par le fac-similé de dom I'onteneau?.

I'abbaye Saint-Genou de l'Estrée semble avoir été la première des fondations auxquelles l'abbé Dodon participa directement. Eille avait été fondée par le conte de Bourges Wifred, et confirmée par Pépin I'r , roi d'Aquitaine, en $830^{8}$. Dodon en reçut la direction, qu'il assuma au moins jusqu'en $843 / 44^{9}$. I ees religieux de Saint-Savin auraient aussi contribué à l'établissement d'une autre des fondations monastiques de Pépin Ier, Saint-Cyprien près de Poitiers, mais la scule source est ici 1'historique dressé par dom listiennot au xiı ${ }^{\mathrm{e}} \mathrm{s.}^{10}$, repris par dom Mabillon ${ }^{11}$ et dom lionteneau ${ }^{12}$ au Xrry"s., et il se peut qu'il y ait eu confusion avec la participation, celle-ci assurée, de l'abbaye de Saint-Savin à la réforme de Saint-Cyprien au début du $x^{e} s^{13}$. lin $\$_{4} \delta$ les chanoines de Saint-

6. MaBLLON, op. cil., t. II, p. 667.

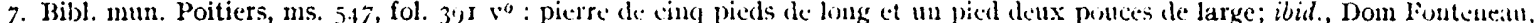
t. I,XXX, p. 529.530. In 18,4 Arcisse de Caumont donna le texte de l'inscription en preciónt les circonstances de sa disparition.

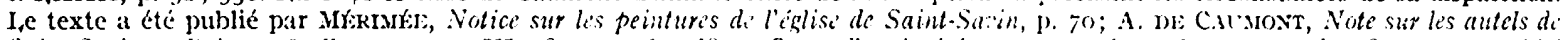

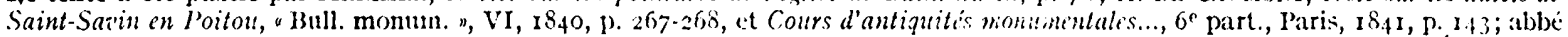

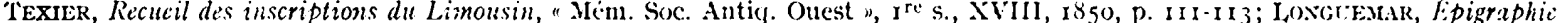

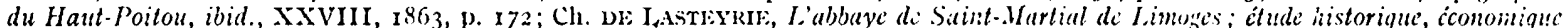

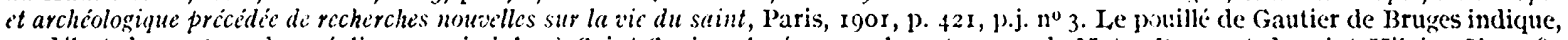
au début du xrve s., deux églises paroissiales a Saint-Savin, placées sous la patronage de jotre.I)ame et de saint Hilaire. Jin r 184 est citée l'église paroissiale Notre-Dame de Saint-Savin, avec la chapelle Saint-Milaire (Arch. depat. Vic?unc, I 11 7. 1 ). Cette eglise: Votre-Dame était situéce sur la place de la République, anciennement place Notre-Dame.

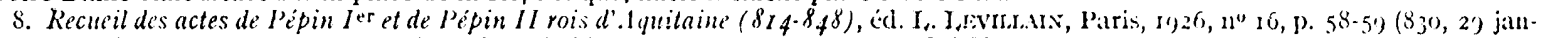

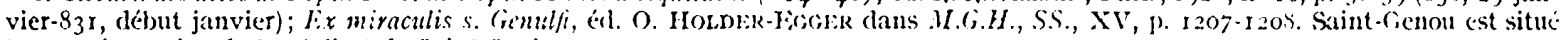
at une soixantaine de $\mathrm{km}$ a l'est de Saint-Savin.

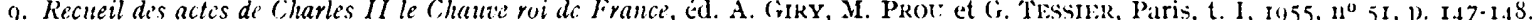
Charles le Chauve renouvelle, à la prière de l'abbé J)odon, les privilèges accordés a l'albaye de l'lestrée par l'épin! Ier, met le monastére sous la protection royale, et permet aux moines de choisir librement leur alblé.

10. H.N., lat. 12756 , p. 47 .

II. Annales ordinis s. Benedicti, t. II, 1). 667

12. Bibl. mun. Poitiers, Dom Fontencau, 1. IXXX, p. $116-417$.

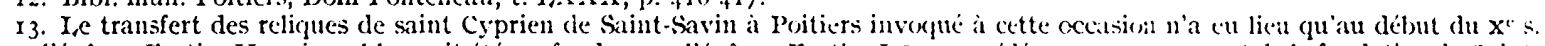

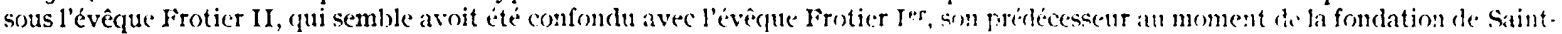
cyprien. 
Martial de Limoges décidèrent d'adopter la tègle monastique. Ils obtinrent l'accord de Charles le Chauve qui tenait alors en leur ville une assemblée générale des évêques et des seigneurs d'Aquitaine, mais ils se refusèrent à choisir parmi eux leur premier abbé et firent appel à Dodon, abbé de Saint-Savin, qui dirigea effectivement l'abbaye pendant trois ans ${ }^{14}$, avant de laisser la charge à un ancien prieur de Saint-Savin, Abbon ${ }^{15}$. Dodon a, en outre, participé à la fondation de l'abbaye de Ruffec, où il fit transférer, de Limoges, le corps de saint Alpinien, disciple de saint Martial ${ }^{16}$, et, avec le concours d'Abbon, à celle de Belvès en Périgord, où il déposa les reliques de saint Justinien ${ }^{17}$.

Dodon assista en 835 à la consécration de l'abbaye d'Alaon en Catalogne, en 848 au concile de Germigny près d'Orléans ${ }^{18}$, et en avril 853 au concile tenu à Soissons ${ }^{19}$. Iin cette dernière assemblée il est cité au premier rang des abbés. Il devait mourir deux mois plus tard.

Ainsi la jeune abbaye de Saint-Savin semble bien avoir eu, sous la direction de Benoit d'Aniane et de Dodon, un rôle essentiel dans le renouveau de la vie monastique en Aquitaine au cours de la première moitié du Ix ${ }^{\mathrm{e}} \mathrm{s}$., avec l'appui des souverains, Charlemagne, Iouis le Pieux, Pépin I ${ }^{e r}$ d'Aquitaine, Charles le Chauve, et des seigneurs de la région, comtes de Bourges et de I,imoges notamment. Ce rayonnement explique, tout autant que les raisons de sécurité - situation écartée de Saint-Savin, solidité de ses remparts - que l'abbaye ait été un des principaux refuges ou une des fréquentes étapes lorsque les moines de l'Ouest, dans la seconde moitié du siècle, durent fuir devant les meurtrières incursions des Normands.

Le repli des moines du Bas-Poitou avait commencé dès le deuxième quart du $\mathrm{Ix}^{\mathrm{e}}$ s., mais ce fut surtout le troisième quart de ce siècle qui vit la grande migration des moines et des reliques de leurs églises ${ }^{20}$. Cette migration est très importante pour notre propos, car elle est essentielle pour la compréhension des inscriptions qui figurent sur les autels et dans la crypte de Saint-Savin. Le corps de saint Maixent fut un temps abrité à Saint-Savin ${ }^{21}$, sans doute après son transport à Redon en Bretagne ${ }^{22}$. Celui de saint Florent fit également étape à Saint-Savin avant d'être déposé à Saint-Gondon en Berry ${ }^{23}$, et les reliques de saint Romard quittèrent alors Châtelaillon, sur la côte, pour être conservées à Saint-Savin²4. Quant au corps de saint Maur, nous connaissons, par Raoul Glaber, les étapes de sa pérégrination après son départ d'Anjou : Saint-Savin, Saint-Martin d'Autun, Baume et plus tard Cluny ${ }^{25}$. I,e choix de Saint-Savin comme position de repli ou comme étape devait s'avérer justifié si l'on s'en rapporte à la Chronique de Saint-Maixent, car l'abbaye fut une des seules de la région à ne pas être détruites par les raids normands ${ }^{26}$.

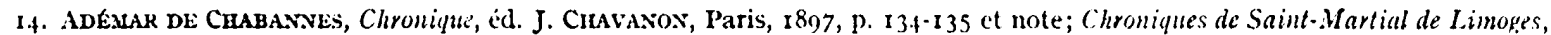
ed. H. DUPLES-AGIER, Paris, 1874 , p. 1 .

15. I,ASTEYRIF, L'abbaye de Saint-Martial de Limoges..., p. 54-55.

16. AA.SS., Avril, III, p. 485 ; R. DE LASTEYRE, fitude sur les comtes et vicomte's de Limoges antérieurs à l'an 1000, Paris, I87, 1). I9-20 et note (" Bibl. Éc. Hautes ĺitudes ", 18).

I7. Gallia christiana, II, col. 1286 et 1489 ; B.N., lat. 12756, p. 49 (dom Istiennot), et Périgord 37 , p. 5 et I6. I'érection du prieuré de Roth en Bas-L,imousin (Gallia christiana, II, 1286) semble etre le fait du seul Abbon (L.AsTEYRIE, L'abbaye de Saint-Martial..., p. 52 et $39 \mathrm{I}$ ), comme le fut la fondation de l'abbaye de Chambon en Combraille (R. I.movzix-LAurotre, Le diocése de I.imoges des origines à la fin du moyen âge, Strasbourg, 1951, p. 62).

18. Annales ordinis s. Benedicti, t. II, p. 568, 643 .

19. Concilia antiqua Galliae, ed. J. SrRvoxd, Paris, t. III, I629, p. 80; R.X., lat. 12756, p. 49.

20. M. Garaud, Les incursions des Normainds én Poitou et lenrs conséquenc's, "Revue historique ", CLXXX, 1937, p. $241 \cdot 267$.

2I. Inventio reliquiarmm s. Marimi, A.A.SS.O.S.B., III/2, p. 486 .

22. AA.SS., Juin, VII, p. 154-155; J. Besly, Histoire des comtes de Poictou ct ducs de (inyenne, Paris, 1647, p. 924-925; Fr. Cotta.s. SaIs, Les monastères du Poitou..., p. 11-12.

23. Inventio reliquiarum s. Marini, p. $486 ; A$ A.SS., Septembre, VI, p. $410-438$, et particulièrement p. 4I 7 . I,es moines avaient dî quitter leur premier établissement, aujourd'hui Saint-Florent-le-Vieil (ch.-1.c., Maine-et-Loire).

24. Inventio reliquiarum s. Marini, p. 486 .

25. Raotu Glaber, Les cinq lizres de ses histoires (900-1044), ed. M. PRor, Paris, 1886, p. 66-67.

26. Furent alors détruits les monastères de Saint-Martin de Vertou, de Saint-Martin de Tours, de Jotre-Dame de I,uçon, de SaintMichel-en-l'Herm, de Saint-Hilaire et de Sainte-Croix à Poitiers, de Saint-Renoit de Quincay. "Conobium Sancti Savini et castrum in quo est, quod Carolus Magnus jussit aedificari, inviolabile mansit solum, caeteris multis destructis quae non occurrit nominare * (cf. supra, n. 3). 
Ce fut en Bourgogne que les reliques des églises poitevines trouvèrent le plus fréquemment refuge. En effet, si celles de saint Martin de Vertou s'arrêtèrent à Saint-Jouin-de-Marnes² ${ }^{2}$, et celles de saint Léger à Ébreuil en Auvergne ${ }^{28}$, celles de saint Philibert de Noirmoutier et de saint Benoît de Quinçay aboutirent à Tournus ${ }^{29}$, les corps de saint Hilaire et de sainte Radegonde furent peut-être un moment transportés à Dijon ${ }^{30}$, et celui de saint Vivant en Auvergne puis à Vergy ${ }^{31}$. Ainsi s'explique tout naturellement, du fait de ces relations nombreuses, que le comte d'Autun Badilon, au surplus originaire d'Aquitaine, ait fait appel à des religieux poitevins pour réformer le monastère Saint-Martin d'Autun. Les moines qui partirent de Saint-Savin étaient au nombre de dix-huit d'après la Vie consacrée à celui qui les dirigeait, saint Hugues. Après avoir œuvré à Autun, is participèrent à la fondation de Gigny, restaurèrent Baume-les-Messieurs, dont un nommé Bernon - peut-être un des moines de Saint-Savin - devint abbé, et participèrent au renouveau de Vézelay. Quand Bernon fut appelé à Cluny pour en être le premier abbé, il était accompagné d'Hugues, qui le conseillait en tout ${ }^{32}$. Dans son testament Bernon recommandera à son successeur les abbayes du Bourg-Dieu et de Massay qui avaient été également rétablies par les religieux de Saint-Savin ${ }^{33}$, foyer de vie religieuse. Elle était alors dirigée par un ami d'Odon, deuxième abbé de Cluny : Aimon, frère de l'évêque de Limoges Turpion d'Aubusson $n^{34}$ et parent du vicomte d'Aubusson ${ }^{35}$. Ces origines familiales expliquent sans doute pour une part l'action réformatrice de l'abbé Aimon en Limousin. Avec le concours de son frère Turpion il restaura l'abbaye de Saint-Augustin de Limoges ${ }^{36}$, puis à la demande d'Aymar de Turenne il assura la réforme de l'abbaye Saint-Martin de Tulle qui, après avoir été détruite par les Normands, était tombée aux mains de laï $\mathrm{cs}^{37}$, enfin il dirigea pendant six ans l'abbaye Saint-Martial de Limoges ${ }^{38}$. Il aurait encore participé activement au rétablissement de l'abbaye Saint-Cyprien où l'évêque de Poitiers Frotier II venait de faire transférer, très probablement de Saint-Savin, le corps de saint Cyprien ${ }^{39}$, et s'il doit bien être identifié avec l'abbé de Saint-Cyprien Aymon, cité à partir de 936, il aurait été également à la fin de sa vie abbé de Saint-Jean-d'Angély ${ }^{40}$. Si l'on ajoute que l'abbaye réformée de Tulle assura la restauration des abbayes d'Aurillac et de Sarlat, que l'abbé de Saint-Cyprien Aymon construisit l'église de Nouâtre et que, à la requête de Guillaume I,ongue-Épée, douze moines de la même abbaye allèrent s'établir à Jumièges ${ }^{41}$, on voit que l'influence de l'abbaye de Saint-Savin n'a cessé, depuis sa fondation, d'être de premier plan dans le mouvement monastique.

27. AA.SS.O.S.B., I, p. 688 .

28. AA.S.S., Octobre, I, p. $443-452$.

29. De translationibus et miraculis sancti Filiberti, éd. R. Pouparorv, dans Monuments de l'histoire des abbayes de Saint-Philibert (Noirmouticr, Grandlieu, Tournus), Paris, 1905, p. 19-70. Le Breviarium de reliquiis que continentur in monasterio Trenorciensi (éd. A. DE Crannasse, Notice sur un manuscrit de la Bibliothèque de la ville de Tournus, "Mémoires Soc. éduenne ", n.s., II, 1873, p. 453), cite les reliques de saint Filibert et aussi de saint Benoit de Quinçay.

30. Acta translationis et miracula s. Prudentii martyris libri quatuor, dans Nova bibliotheca manuscriptorum librorum, éd. Ph. I,ABBE, t. II, Paris, 1657, p. 6II.

3r. AA.SS., Janvier, II, p. 95, saint Vivant ou Vivence. Vergy, cuo Reulle-Vergy, c. Gevrey-Chambertiu, Côte-d'Or.

32. R. I,ouis, De l'histoire à la légende. Girart, comte de Vienne (... 819-877) et ses fondations monastiques, Auxerre, I946, t. I, p. 154. 155; A A.SS., Avril, II, p. 761-770, De s. Hugone monacho Aedicensi et priore Enziacensi o.s.B. in Gallia. On observera la similitude entre la fondation de Saint-Savin et la restauration d'Autun, avec un même nom de Baidilus, clerc palatin dans le premier cas, comte palatin dans le second, et on notera que l'itinéraire de saint Hugues est exactement le même que celui des reliques de saint Maur. Douze religieux de Saint-Savin ou de ses dépendances auraient participe à la fondation de Cluny (dom Fonteneau, $t$. I,XXX, p.4I9424).

33. Ibid., p. 430 .

34. Bernard ITIER, Chronicon, dans Chroniques de Saint-Martial de Limoges, éd. Duplìs-AGIER, p. 41.

35. Chronicon Sancti Maxentii, éd. Verdov, P. 94; R. I, movzn-I.AMotus, Le diocèse de Iimoges..., p. 43, 68: Turpion est cité a partir de 905 et est mort en 944.

36. Dom Fontencau, t. LXXX, p. 429.

37. Baldze, Historia Tutelensis, Paris, I7r7, col. 325 ; Annales ord. s. Benedicti, t. III, 1706, p. 347 et $404 \cdot 405 ;$ H.F., IX, p. 573.

38. Bernard ITIER, Chronicon, p. $4 \mathrm{I}$.

39. Cartulaire de l'abbaye de Saint-Cyprien de Poiticrs, éd. I. ReDET, P'oitiers, I874 ("Arch. histor. Poitou ", 3), n" 183, p. II7; $11^{\circ}$ I9r, p. 125.

40. I a chronique de Saint-Maixent dit Aimon abbé de Saint-Jean-d'Angély et de Saint-Cyprien en 944 , mais la chronique de Bernard Itier doune Aimon comme mort en 942 , trois ans avant son frère Turpion décédé en 944 .

41. Dom Fonteneau, t. LXXX, p. 428; Gumlaume DE Juamegs, Historia Normannorum, 1. III, 8 (lP.I.., CXI,IX, 807); Cartulaire de l'abbaye de Saint-Cyprien, éel. REDET, n² 290, p. I 84 , v. 943. 
A une date incertaine, mais sans doute à l'occasion des dernières incursions des Normands en Poitou, à la fin du Ix ${ }^{\mathrm{e}}$ ou même au $\mathrm{x}^{\mathrm{e}} \mathrm{s}^{42}$, les moines de Saint-Savin enfouirent les reliques de l'abbaye dans l'église, en des lieux divers et sans le moindre signe de repère. Il y avait là les corps des saints Marin, Prudence, Maixent, Romard et Florent, et aussi celui de saint Savin, qui auparavant avait été transporté en Berry où il était resté trente ans avant d'être ramené à SaintSavin. Bientôt tous ceux qui avaient participé à cette mise en terre des reliques disparurent, et plus personne ne connut l'emplacement exact des corps saints ${ }^{43}$. Au début du XI ${ }^{\mathrm{e}} \mathrm{s}$. Guillaume le Grand, duc d'Aquitaine, restaura la discipline régulière à Charroux, en expulsant l'abbé Pierre qui avait obtenu sa charge par simonie, et en le remplaçant par l'abbé de Saint-Savin Gombauld ${ }^{44}$. Celui-ci eut alors pour successeur à Saint-Savin le prévôt de l'abbaye Odon. La comtesse de Poitou Aumode qui venait de mourir avait, à la requête de Gombaud, laissé à l'abbaye, " pour le salut de son âme ", une importante somme d'argent ${ }^{45}$. Grâce à cet argent, de grands travaux furent entrepris dans l'église abbatiale par l'abbé Odon, et au cours des travaux furent mis au jour les ossements de saint Marin et les autres reliques dissimulées précédemment. Aumode, épouse de Guillaume le Grand en 997 ou 998, était morte en 101046. Odon est encore cité comme abbé de Saint-Savin en $1040^{47}$. Mérimée nous rapporte qu'« à l'angle rentrant du croisillon nord, le long de la muraille orientale du transept, entre le mur nord et l'abside, on a trouvé en I 844 un tombeau de pierre de forme trapézoïdale, composé de deux pièces : l'une en façon d'auge, avec une place creusée et arrondie pour la tête du cadavre, l'autre servant de couvercle, plate en dessous et présentant à l'extérieur un angle très obtus. Sur le côté plat, à l'intérieur, on lit l'inscription suivante, tracée en creux : Hic requiescit Odo abbas ${ }^{48}$ ". Les caractères de l'épitaphe sont fort grossiers, et l'étude paléographique fournit un certain nombre d'éléments concordants pour situer le texte dans la première moitié du $\mathrm{XI}^{\mathrm{e}} \mathbf{s}^{49}$. Il doit bien s'agir de l'épitaphe de ce même abbé Odon sous la direction duquel avait été entreprise la reconstruction de l'abbatiale.

On peut penser, à partir de la situation même du tombeau, que les travaux étaient alors achevés pour le chœur et pour le transept, données chronologiques qui s'insèrent parfaitement dans ce que nous savons de l'histoire de la région à cette époque. Au début du $\mathrm{XI}^{\mathrm{e}} \mathrm{s}$. Guillaume le Grand établit

42. M. Garatd, Les incursions des Normands en Poitou... (supra, n. 20), cite comme dernières alertes les années 919/37, le milieu du $x^{\circ}$ s. et enfin le début du $x^{\mathrm{e}}$. Ce fut dans les années 930 qu'Éble, évéque de Limoges, trésorier de Saint-Hilaire-le-Grand et abbé de Saint-Maixent, fit construire une enceinte fortifié autour de la cathédrale de Limoges, du chapitre de Saint-Hilaire et de l'abbaye de Saint-Maixent (Chronicon Sancti Maxentii, éd. VerDon, p. 93).

43. Inventio reliquiarum s. Marini (à partir d'un ancien bréviaite manuscrit de Saint-Savin), p. 486.

44. Ademar de Chabannes, Chronique, éd. Cravanon, p. 184. Ira lettre du duc Guillaume à l'abbé Aribert lui demandant l'envoi d'une dizaine de moines à Charroux (Du ChesNe, Historiae Francorum scriptores, IV, Paris, nouv. éd., I74I, p. I9I-I92; éd. J. BEsLx, Histoire des comtes de Poitou..., p. 340) a généralement été mise en relation avec la venue à Charroux de l'abbé de Saint-Savin. MabiLlos (dans ses Annales ord. s. Berredicti... IV, I707, p. 240) place cette lettre vers ror4 et suggère de voir en Aribert le prédécesseur de Gombaud. Dom P. DE MonsaberT [Chartes et documents pour servir a l'histoire de l'abbaye de Charroux, Poitiers, I9ro (" Arch. hist. Poitou ", 39), p. 90-9I et n. I] réédite cette lettre et la date de 1032/64, en estimant que cet Aribert serait plutôt le célebre abbé de Marmoutier, Albert.

45. Inventio reliquiarun s. Marini, p. 486 : "Tempore autem non pauco prius evoluto factum est, sub sanctac videlicet recordationis diebus Gungaldi abbatis, ut Odo qui sub ejus patris regimine praepositi fungebatur officio, cui et in regimine decenti meruit subrogari licentia et deprecatione ipsius patris, non modica pecunia ab Almone, Pictavorum comitissa, ab hac vita recedente, suscepta quantitate, quatenus eam quo utilius proficere sciret ad ipsius remedium animae ordinaret. " $L$ 'abbé Gombaud, qui intervint auprès de la comtesse, serait, d'après Adémar de Chabaunes, parti pour Charroux vers 1014.

46. Dom J. CoQCeT, Le tombeau prísumé de la comtesse Aumode à Ligugé, dans "MIélanges E.-R. I,ABANDE ", Poitiers, I974, p. I6I167,2 h. $-t$.

47. Cartulaire de l'abbaye cardinale de la Trinité de Vendóme, éd. abbé Ch. MétaIs, Paris, t. I, I893, no 39, p. 89; 40, p. 92 (3I mai 1040).

48. Mérnméte, Notice sur les peintures de l'iglise de Saint-Savin, p. 10.

49. Les deux $C$ sont carrés, le $S$ de requiescit est tracé à la façon d'un $Z$, ce qui correspond probablement a une inversion de la lettre, forme qui se trouve essentiellement au $x^{\mathrm{e}} \mathrm{s}$. : en 1001 à Trets, en ro48 à Marseille, mi-xI ${ }^{\mathrm{e}} \mathrm{s}$. a Saint-Remi de Reims, v. 1060 à Narbonne, en ro69 à Elne, mais aussi dans l'émail d'Étienne de Muret conservé au musée de Cluny. La hauteur des lettres varie de $6,5 \mathrm{~cm}$ à $12 \mathrm{~cm}$. L'inscription est trés proche de celle de l'évêque de Limoges Giraud à Charroux en 1022 , ou de celle qui rappela vers I03I l'apostolicité de saint Martial à Limoges, comme de toutes les inscriptions du Poitou à cettc époque. La disposition du texte à l'intérieur est sans doute un témoignage d'humilité; elle rejoint une pratique courante qui consistait à inscrire le nom du défunt sur une plaque de plomb, placée à l'intérieur du sarcophage. 
définitivement l'abbaye de Maillezais et fait transporter à Poitiers, à l'occasion d'un concile, le corps de saint Maixent ${ }^{50}$; sa femme Aumode est la bienfaitrice de Ligugé, et est inhumée dans la crypte de l'église abbatiale ${ }^{51}$. Fin rorz l'abbesse de Sainte-Croix de Poitiers, Belliarde, fait faire des travaux dans l'église Sainte-Radegonde, et y retrouve le corps de sainte Radegonde ${ }^{52}$. A la même date l'église Saint-Martial de I,imoges est détruite pour être agrandie ${ }^{53}$; le chevet en est consacré en I028, et on constate que son plan est exactement le même que celui de Saint-Savin, cinq absidioles au pourtour du choeur, une dans chacun des croisillons du transept, et une même disposition des clochers ${ }^{51}$. I'abbaye de Noyers est fondée en I0.30, celle de 'Talmont en I040, la collégiale de Saint-Nicolas de Poitiers vers $1050^{55}$, et dans le même temps l'abbaye de Nanteuil est restaurée ${ }^{56}$. Entre I04I et 1050 ont lieu les dédicaces des abbayes de Saint-Florent près de Saumur, de Charroux, de Saint-Michel-en-l'Herm, de Saint-Jean-d'Angély, ainsi que de la collégiale Saint-Hilaire-le-Grand, tandis que le tombeau de saint Maixent sera reconstruit en $1059^{57}$.

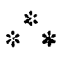

Si les documents soulignent l'importance des fondations, des campagnes de constriction, des remises en honneur des reliques des saints au cours de la première moitié du XI $\mathrm{I}^{\mathrm{e}} \mathrm{s}$. dans, le: nord de l'Aquitaine, il reste à étudier un ensemble épigraphique exceptionnel, celui des inscriptions des autels de Saint-Savin. En effet nous possédons, directement ou indirectement, les inscriptions des sept autels dı déambulatoire ct du transept, les fragments de deux autres autels, et un relevé partiel du texte inscrit sur l'autel matutinal.

In premier lieu il faut citer un fragment d'autel qui présente des caractères particuliers. Il s'agit de l'angle d'une table qui offre un rebord en saillie orné de moulures, comme on en faisait à l'époque franque. Il fut trouvé par le doyen de Saint-Savin au cours du dernier tiers du siècle dernier, dans la crypte de Saint-Marin, et il fut signalé par deux articles ${ }^{58}$, mais à une date inconnue on le transporta au baptistère Saint-Jean de Poitiers, où il est indiqué à tort comme provenant du baptistère lui-mème. Sur le dessus de la table et sur la tranche sont tracés des graffiti. Ce fragment se distingue des autres autels par sa forme, puisque les autres tables d'autel sont régulières, sans moulures, et par l'absence d'inscription de consécration ${ }^{59}$. Quant aux graffiti, il s'agit de noms propres : VVIDO, BERENGARI..., MARINI, ...FRED., BER..., le reste difficilement déchiffrable. On a relevé de semblables graffiti sur un certain nombre d'autels des $\mathrm{vI}^{\mathrm{e}}-\mathrm{vir}^{\mathrm{e}} \mathrm{s}$., à Auriol, Ham, Saint-lelin, Vouneuil-sous-Biard aux portes de Poitiers ${ }^{60}$, Minerve, Montmartre ${ }^{61}$,

jo. Chronicon Sailcti .Maxintii, ed. VeruoN, p. 119-120.

$5 \mathrm{x}$. Jom Coocex, Le tombeau présumi..., p. 162-163.

52. R. IAvreat et J. Mrcmacd, Confus des inscriptions de la France médiciali. I : Poitou-charintes. I : Ville de Poiticrs, Poitiers, $1974,1^{0} 79$, p. $9.5-96$.

53. ADEMaR DE Chabanatis, Chronique, ed. cit., p. 172.

34. Ch. DE IAsterkis, L'abbayc di Saint-Martial de Limoges... (supra, n. 7), p. $29+$ et 3 I.4.

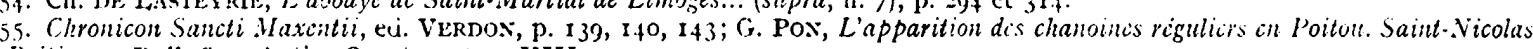
de Poitiers, "Bull. Soc. Antiq. Ouest ", te s., XIII, 1975, p. 55-70.

56. II. Beacchet-Filear, Poulle du diocise de Poitiers, Niort Poitiers, $1868, p$. 17.

57. Chronicon Sancti Maxintii, éd. Verwos, p. Ifo-I 44 et 150.

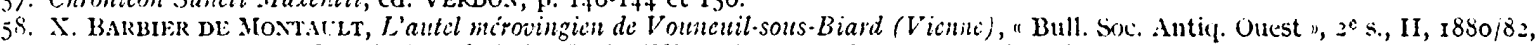

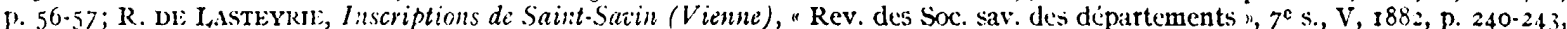
; fig. C'est l'abbé Lebrr x qui signale dans L'abbaye et l'iglise de Saint-Sain (Poiticrs, 1888 , p. 99) que ce fragment fut trouvé dant la crypte Saint-Marin.

59. Toutefois on ne pent exclure la possibilité d'une inscription sur la face antérieure de la table s'il s'agit ici d'un angle de la face postéricure.

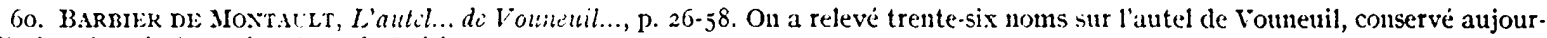
a'hui all haptistère Saint-Jean de Poitiers.

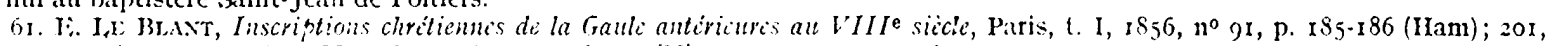

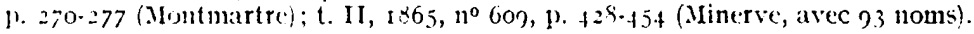


ct récemment on en a découvert, datables du $\mathrm{IX}^{\mathrm{e}} \mathrm{s}$., sur la face postétieure et les deux faces latérales d'un autel de Moissac ${ }^{62}$. Robert de Irasteyrie suggérait en I882 d'y voir les signatures de pieux pèlerins ou les noms de moines de l'abbaye. Nous reposerons la question en examinant l'ensemble des nombreux graffiti des autels de Saint-Savin, mais il faut bien ici avouer une particulière difficulté pour proposer une datation. Les trois seuls auteurs qui aient mentionné ces graffiti les situent, l'un, Barbier de Montault, au vir ${ }^{\mathrm{e}}$ ou peut-être au début du viI ${ }^{\mathrm{e}}$ s., le deuxième, Robert de I asteyrie, aux $\mathrm{x}^{\mathrm{e}}$ ou $\mathrm{x}^{\mathrm{e}}$ ou peut-être $\mathrm{x} \mathrm{I}^{\mathrm{e}} \mathrm{s}$., tandis que Rohault de Fleury en donne une reproduction avec, en légende, la mention : "fragments de l'autel carlovingien ${ }^{63}$ ". Il est certain que telle ou telle lettre peut être comparée à des formes que l'on rencontre en Poitou de la fin de l'époque mérovingienne, hypogée de Mellebaude à Poitiers, à la fin de l'époque carolingienne, peintures murales de Saint-Pierre-les-Églises. L'histoire même de Saint-Savin conduit à écarter la première datation, les différences par rapport aux autels $d u x^{e}{ }^{e}$ s. amènent à rechercher plutôt une autre période de construction, c'est-à-dire à situer ce fragment de préférence aux $\mathrm{IX}^{\mathrm{e}}-\mathrm{x}^{\mathrm{e}} \mathrm{s}^{61}$.

Les inscriptions des autels du déambulatoire et du transept ont été transcrites pour la première fois par dom Claude Esstiennot à la fin du xviI ${ }^{\mathrm{e}} \mathrm{s}^{6 \overline{5}}$, et elles furent mentionnées en I 7 I 7 par dom Martène et dom Durand dans leur Voyage littéraire66. En I 669 les religieux de Saint-Savin avaient déposé les tables d'autel du déambulatoire et les avaient collées contre la muraille du fond de chaque absidiole; l'autel du bras sud du transept fut conservé pour servir d'appui à un retable grec; l'autel du bras nord du transept devait être détruit au début du XIx ${ }^{e}$ s. parce qu'il gênait l'installation provisoire d'une sacristie à cet endroit' ${ }^{67}$. Quand dom Fonteneau vit les autels à la fin $d \mathfrak{u} \mathrm{XVII}^{\mathrm{e}} \mathrm{s}$. et en reproduisit les textes en fac-similés, il ne put lire que ce qui était inscrit sur les faces antérieures et latérales des autels du déambulatoire et du bras nord du transept; quant à l'inscription de l'autel du croisillon sud, la seule qui fût en sa situation primitive, il ne put la voir que jusqu'à la moitié de la face latérale droite de la table, le reste étant caché par une colonne du retable ${ }^{68}$. Avant 1840 Arcisse de Caumont fit deux voyages à Saint-Savin, et obtint dı curé l'autorisation d'enlever la grossière maçonnerie qui dissimulait une partie du texte de deux autels du déambulatoire ${ }^{69}$. Prosper Mérinée puis Longuemar connurent ces autels dans ce même état ${ }^{70}$, mais l'abbé Lebrun, curé de Saint-Savin en I86I, fit replacer en I 864 les tables sur leurs anciennes bases, ce qui permit à $B$. Ledain de donner une lecture de toutes les faces ${ }^{71}$. Mais ces auteurs, de même qu'Élisa Maillard en $1926^{72}$, se sont bornés à donner des relevés, dont ancun d'ailleurs n'est irréprochable. Il faut donc essayer à la fois de fournir le meilleur état possible, et d'étudier plus en profondeur ce dossier épigraphique. Pour ce faire nous considèrerons successivement les autels du déambulatoire puis du transept.

I'autel de la première absidiole nord du déambulatoire est aujourd'hui dédié à sainte Anne. Il

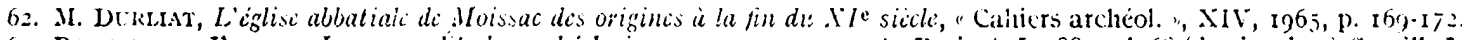

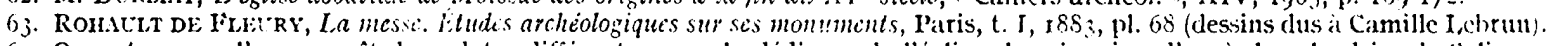

64. On notera que l'on conmait deux dates differentes pour la dédicace de l'église: le 7 jarvier, d'apres le calendrier de soliguace

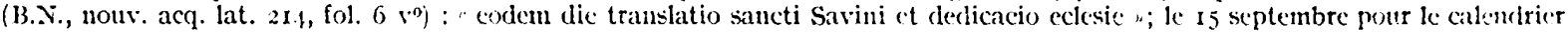
de Saint-Savin au xvir!" s. (Arch. depart. Vienne, I II $7 / 9$ ).

65. 13...., lat. 127,56 , p. $77-78$. I, bendictin Claude Fistiennot de La Scrre avait commence son recucil en r673; ses nusis. sont entrés en 1795 et 179,6 a la biibliotheque nationale avec ceux qui provenaient de Saint-(jermain-des-Prés; ils y sont conservés sous les numeros $12755 \cdot 12758$ du fourls latin.

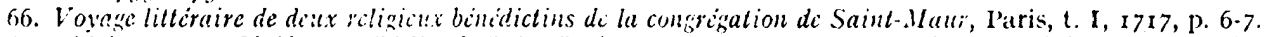

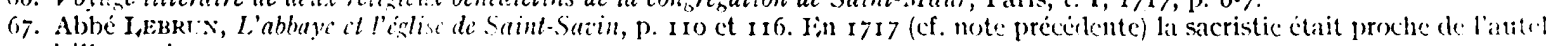
du croisillon sud.

68. Bibl. mun. Poiticrs, ms. 57 , fol. 393 . Cf. figure 6.

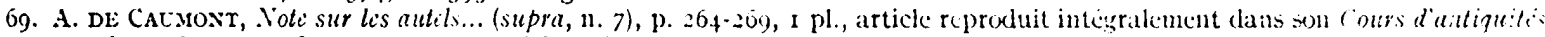
nomumentales..., $6^{\mathrm{c}}$ part., $18.1 \mathrm{r}, \mathrm{p}$. $139-1+3$ et Atlas, pl. 82.

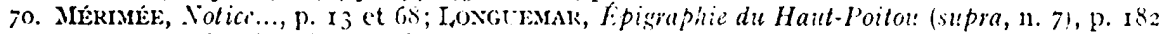

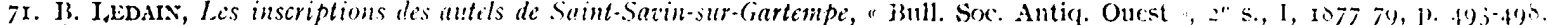

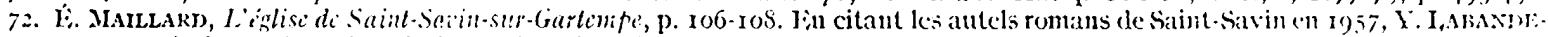

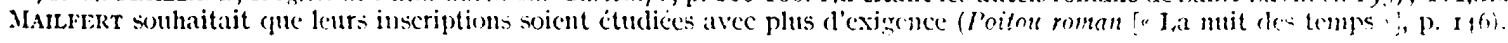


était primitivement consacré aux vierges, comme l'atteste l'inscription ${ }^{73}$ qui court sur la face antérieure et la face latérale droite :

\section{TSTE ALTARIS POLLET IN HONORE SANCTARUM AGATA CECILIA AGNES LUCIA SAVINA FERCINCTA.}

"Cet autel a pouvoir en l'honneur des saintes Agathe, Cécile, Agnès, I ucie, Savine, Fercincte. "

Les quatre premières vierges sont célébrées dans toute l'Église et leurs noms étaient cités au canon de la messe. Les deux dernières sont honorées plus particulièrement à Saint-Savin. Sainte Savine a son tombeau dans la crypte principale, et nous l'étudierons à ce moment-là. Sainte I'ercincte est représentée dans les peintures murales de la même crypte. D'après dom Fonteneau il s'agirait d'une vierge et martyre, recluse à Tolède en Espagne, persécutée sous Dacian, préfet à Valence au temps de Dioclétien ${ }^{74}$. Elle était honorée au $\mathrm{x}^{\mathrm{e}} \mathrm{s}$. à Lurais, église dépendant de l'abbaye de Saint-Cyprien de Poitiers ${ }^{75}$, et l'abbaye de la Trinité de Poitiers, fondée à cette même date, possédait de ses reliques ${ }^{76}$. Le nom de Ferrocinctus est inscrit sur un sarcophage mérovingien d'Antigny aujourd'hui conservé au baptistère Saint-Jean de Poitiers. La sainte ne figure dans aucun calendrier. L'autel de la deuxième absidiole nord du déambulatoire est actuellement placé sous le patronage de saint Joseph. L'inscription qui commence par la face antérieure et se poursuit par les faces latérales droite puis gauche montre que le patronage initial était celui des martyrs :

\section{+ PREPOLLET IN HOC ALTARE PRUDENCIUS MARTIR CUM CLEMENTE PAPA + + ETT LAURENCIO ARCHIDIACONO NECNON GEORGIO + ATQUE MAURICIO ET OMNIUM MARTIRUM + \\ "Prudence, martyr, montre tout son pouvoir en cet autel, avec le pape Clément, l'archi- diacre Laurent, et Georges et Maurice et tous les martyrs. ")}

En outre sur la face postérieure de la table plusieurs noms sont inscrits dans les caractères mêmes de l'inscription de consécration, et sur deux lignes :

$\begin{array}{lll}\text { AB } & \text { HERMEN } \\ \text { BER } & \text { BERA } & \end{array}$

et des graftiti qui sont à peine tracés et n'ont encore jamais été signalés donnent trois nouveaux noms :

$$
\text { TETBERGA S'TEPHANUS et, semble-t-il, GONDEBALDUS }
$$

On peut sans hésitation écarter l'identification, proposée par Caumont, de Clément avec le second pape de ce nom mort en I047, pour y reconnaître le quatrième souverain pontife, Clément I qui vivait à la fin du I ${ }^{\mathrm{er}} \mathrm{s} .{ }^{77}$, mais la difficulté est de savoir quel est le saint Prudence ici honoré.

73. I,edain est le premier qui en ait donné un relevé complet et exact.

74. Dom louteneau, t. XXIX, p. 315: "Sainte Iercincte, vierge et martire, etant recluse a Tolède en Lspagne, après avoir enduré beaucoup de traverses par Dacian, trouva moyen de venir à Poitiers selon aucuns. Sa féte est le 13 novembrc."

75. Cartulaire de l'abbaye de Saint-Cyprien de Poitiers, éd. REDET, $1^{\circ} 4$, p. 6. Lurais, c. Tournon (Indre).

76. B.N., lat. I2755, p. 107, état des reliques conservées en l'abbaye de la Trinité avant 1500 : saintes Radegonde, Opportune, Ferocincta, Catherine, etc.

77. Clément I pape figure au calendrier des saints de l'Église de Poitiers au début du XIr ${ }^{\mathrm{e}}$ s. (Bibl. mun. Poitiers, ms. 40, fol. $13 \mathrm{v}^{\circ}$ ), dans celui de l'abbave de la Trinité de Poitiers au xive s. (ibid., ins. 430, fol. $156 \mathrm{v}^{\circ}$ ), et est cité dans un bréviaire du diocèse de P'oitiers à l'usage de l'abbaye Saint-1filaire ant $\mathrm{XV}^{\mathrm{c}}$ s. (ibid., ms. 26, fol. 6). Pour la photographic puis l'estampage de cette inscription, cf. $1 \mathrm{i}: \mathrm{s} \cdot \mathrm{I}-4$. 
L'évêque de Tarazona, de ce nom, mort au ve s., est fêté le 28 avril; l'évêque de Troyes du même nom, espagnol d'origine, décédé en 86I, est honoré le 6 avril; les reliques d'un saint Prudence martyr auraient été trouvées au $\mathrm{Ix}^{\mathrm{e}} \mathrm{s}$. et portées alors au monastère de Bèze en Bourgogne, où elles étaient vénérées le 6 octobre $^{78}$. Or le calendrier propre à Saint-Savin place au I6 novembre la fête de saint Prudence, versificatoris et martiris ${ }^{79}$. On se trouve dans l'impossibilité de trancher, d'autant plus que saint Prudence est régulièrement cité dans les calendriers des saints, tous, il est vrai, en provenance de Troyes, au 6 avril; seul un bréviaire de Limoges du xrve $s$. mentionne un Prudence martyr au I3 novembre ${ }^{80}$. Prudence de Troyes fut poète mais non martyr, et faut-il nécessairement écarter l'auteur de la Psychomachie simplement parce qu'il n'a pas été reconnu comme saint? On notera par ailleurs que les relevés donnés jusqu'ici de cette inscription aboutissaient à des incohérences en proposant une lecture suivie de gauche à droite, c'est-à-dire en plaçant les noms de la face postérieure entre ceux de saint Georges et de saint Maurice.

I'inscription de l'autel de l'absidiole centrale est la seule qui commence sur la face latérale gauche. I.e relevé en était déjà donné de façon à peu près exacte par dom Estiennot au Xvir ${ }^{\mathrm{e}} \mathrm{s}$. :

\section{HERMEN \\ MILES IN ORBE POTENS PROPRIO QUI SANGUINE FUSO BABTISTA JOHANNES INCLITUS MARTIR MARINUS HIC REQUIESCIT.}

Lire HERMEN (Estiennot), HERMENS (Martène et Durand), HERMENONIUS (Ledain), ne changeait rien à l'affaire, c'est-à-dire ne permettait pas de donner un sens satisfaisant au texte. Or la simple recherche des saints dont le nom commençait par ces six lettres menait immédiatement à Hermenegildus, fils du roi wisigoth arien Leovigildus, qui se convertit au catholicisme, prit au baptême le nom de Jean, se révolta contre son père, fut vaincu et mis à mort pour sa foi ${ }^{81}$. Il faut donc commencer l'inscription par:

HERMENEGILDUS MILES IN ORBE PO'TENS, etc.,

et il devient facile de traduire :

" Hermenegilde, soldat puissant par toute la terre, devint un Jean Baptiste par l'effusion de son propre sang. L'illustre martyr Marin repose ici."

On peut penser qu'il y a dans la formule employée une double intention : Hermenegilde a pris au baptême le nom de Jean, et il a, en même temps, été par son sacrifice le " précurseur " de l'Église catholique d'Espagne ${ }^{82}$. Son culte a été relativement répandu si l'on en juge par le nombre des hymnes qui lui ont été consacrées ${ }^{83}$. Il n'est pas cité dans l'état des fêtes propres à Saint-Savin

78. A.SS., Octobre, III, p. $333-378$

79. Arch. départ. Vienne, I II $7 / 9$.

8o. Abbé V. Leroquars, Les bréviaires manuscrits des bibliotheques publiques de France, Paris, t. IV, 1934, nº 817, p. 211 .

81. Grécorre De Tours, Historiae Francorum, éd. (;. Collon, Paris, I893, t. I, p. I81 et ss. : Conversus est ad legem catholicam, ac, dum crismaretur, Johannis est vocitatus ". Voir aussi AA.SS., Avril, VII, p. I35-I 39 .

82. L' '́glise d'ispagne devient ofheiellement catholique avec la conversion de Récaréde, frère d'Hermenegilde. Vincent de Beauvais dans son Spcculum historialc, XII, 35 (Douai, 1624, p. 860), De sancto Ermenegildo rege ct martyre, le souligue expressément : " Post cujus mortem Recaredus rex... fratrem martyrem sequens ab Arrianae haeresis pravitate conversus est, totamque Vuisigothorum gentem ita ad veram perduxit fidem. "

83. Le Repertorium hymnologicum d'C. Chevalier (Louvain, t. I-VI, 1892-1920) donne treize téférences à Hermenegildus. E. HüBNer (Inscriptiones Hispaniae christianac, Berlin, $1871, n^{\circ} 76$, p. 22) cite une table de marbre avec un texte nommant Hermenegilde : " + In nomine Domini anno feliciter secundo regni domni nostri Erminigildi regis, quem persequitur genetor suus domnus I,ivigildus rex in cibitate Ispalensi, ducti Aione. : 
qui a été dressé au $\mathrm{XrIII}^{\mathrm{e}} \mathrm{s}$., et nous avons vu que les bénédictins Eistiennot, Martène et Durand ne savaient plus qui était cet Hermen. Par contre il est mentionné dans un calendrier de l'abbaye de Solignac au début du $\mathrm{xII}_{\mathrm{I}}^{\mathrm{e}} \mathrm{s}{ }^{84}$, ainsi que dans les calendriers plus tardifs de l'abbaye de la Trinite ${ }^{8.5}$ et du chapitre de Saint-Hilaire-le-Grand de Poitiers ${ }^{86}$. La forme de l'inscription est nettement plus soignée que celle des inscriptions des autres autels, sans off rir pour autant des lettres très différentes. La langue elle-même surprend par un souci d'élégance qu'on chercherait en vain dans les autres inscriptions; l'expression sanguine fuso se rencontre dans une inscription métrique du début du $\mathrm{XII}^{\mathrm{e}} \mathrm{s}$. à Spire ${ }^{87}$. En fait on s'aperçoit que cette expression correspond aux deux derniers pieds d'un hexamètre qui commence au début de la face antérieure de l'autel, c'est-à-dire à miles. I a fin du texte consacré à Hermenegilde répond elle aussi aux règles de la métrique, mais on n'aura sans doute pas su comment placer le nom même du saint, ce qui aura amené à le graver sur la face latérale gauche, position exceptionnelle non seulement à Saint-Savin mais pour des inscriptions de consécration d'autel en général. Dans trois autres autels de Saint-Savin les débuts des inscriptions, sur les faces antérieures, se rapportent à des patronages généraux qui n'impliquent pas nécessairement la possession de reliques, alors que les textes se terminent par la mention de saints dont les reliques étaicnt vénérées en l'abbaye, saintes Savine et Fiercincte, saints Maixent, Florent et Romard. Si Hermenegilde n'est pas nommé au calendrier de Saint-Savin, c'est sans doute parce que cet autel de l'absidiole centrale est d'abord l'autel de saint Marin, second patron de l'abbaye ${ }^{88}$, fêté au Xvirie $\mathrm{s}$. avec une solennité égale à celle de saint Savin, et qui figure également dans deux bréviaires de l'Église de Poitiers ${ }^{89}$. Si l'on s'en rapporte à un bréviaire manuscrit de Saint-Savin cité par Jean Mabillon, Marin était un ermite et martyr de Maurienne du vini ${ }^{\mathrm{e}}$ s., dont les reliques avaient été apportées à Saint-Savin avant les invasions normandes; la tradition voulait qqu'elles aient été données par Charlemagne ${ }^{90}$. L'inscription qui lui est consacrée est la même, à l'ordre près, que celle qui fut trouvée dans son tombeau en 1670 : Hic requiescit Marinus inclytus martyr ${ }^{91}$. I a crypte située sous cet autel est dite crypte de saint Marin. Sur la face postérieure de l'autel des graffiti ont été relevés. Les noms de TETBERGA, déjà noté, et de AGNEss, sont parfaitement lisibles, mais celui de MATEUS reste incertain.

L'autel suivant est aujourd'hui dédié à saint Hilaire. L'inscription n'a pu ètre lue complètement qu'après le rétablissement de la table à la fin du siècle dernier. Toutefois l'ordre de lecture, et donc le sens, doivent être corrigés :

\section{(face antérieure) - CONFESSORES AC PRESULES CHRISII HIC SACRA VTNERANTUR ARA HYLARII MARTINI}

\footnotetext{
84. B.X., nouv. acq. lat. $2 I_{f}$, fol. II $^{0}$, aux ides d'avril : "In Hispania sancti Hermenegildi, qui ob fidei catholice confessionem securi in capite percussus reguum celestem pro terreno rex et martir intravit. "

85. Dibl. muin. Poitiers, ms. 4.50 (180), martyrologe-obituairc du xvic s., fol. 5 t, avec exactement le même texte que dans l'obituaire de Soliañac cité à la note précédente.

S6. Calcndarium sancturum quorum on cinm in ecclesia Sancti Hilarii celebratur, Poitiers, 1783, au 13 avril. Hermenegilde, roi et

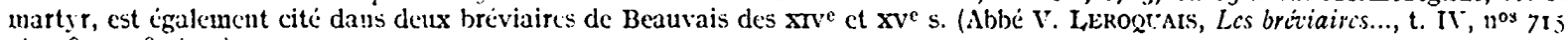
et 718, p. 18 et 24$)$.

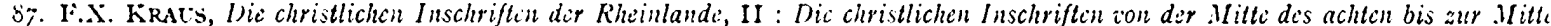
des dicizehnten Jahrhutnderts, litibourg en Br./Leipzig, 1894, p. 65 : vase à cau bénite en bronze doré de la cathédrale de Spire, offert par l'abbé Berthold (1116;19).

8S. Arch. départ. Vienne, I HI $7.9: 2$ mars, "translatio s. Marini secundi patroni ecclesiac, dupl. maj. 3 ord. "; I mai, "inventio s. Marini tuartiris, dup. maj., 3" ord. "i; 24 novembre: "S. Marini martiris, hujus monasterii patroni minus principalis, dup. I $^{\text {ae }}$ classis,

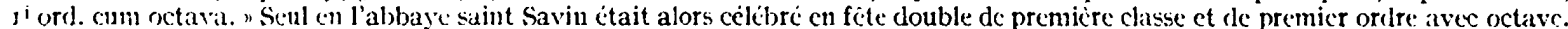
Oritr: et clasec n'ont éte introduits dans la liturgic qu'i la fin de l'Ancien Régime. Je remercie ici dom Becquet, de I,iguge, des préci. sions qu'il a bien voulu me fournir is ce sujet.

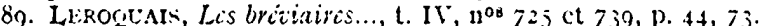

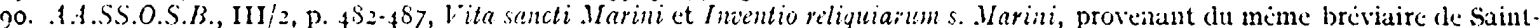
Savin. Dom Jistiennot lui aussi rapporte a Charlemayne le clon des reliques de Marin à Saint-Savin (B.N., lat. I2756, p. 78-79). Marin n'est conmu que par ces textes.

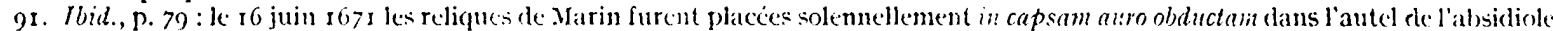
l'axe du reambluatoire.
} 
(face latérale droite) MARCIALIS + HIC CONFESSORES LUCIDI ADJUTOR MAXENCIUS ADQUE

(face postérieure) FLORENCIUS.

"Les confesseurs et évêques du Christ sont vénérés ici en l'autel sacré d'Hilaire, Martin, Martial; ici les illustres confesseurs Adjutor Maixent et Florent."

Lin outre sous le nom de Florent est gravé : YSIMBER, et sont tracés en graffiti : STIPPHANUS, AENOR, OTBFRGA, tandis que la face latérale gauche porte, en caractères identiques à ceux de l'inscription principale : HERMENONIUS ${ }^{92}$. I'association des saints évêques de Poitiers, Tours et Limoges n'a rien pour surprendre. Fille se rencontre dans l'inscription d'un des autels de Montierneuf de Poitiers à la fin du $\mathrm{XI}^{\mathrm{e}} \mathrm{s}$., et elle figure dans les litanies d'un missel et pontifical du diocèse de Luçon au xires s.9. Adjutor qui, en devenant abbé au $v^{\mathbf{e}}$ s., prit le nom de Maixent, et Florent, prêtre au Mont-Ǵlonne, alors en Poitou, au vi ${ }^{\mathbf{e}} \mathbf{s}$., se trouvent l'un et l'autre au calendrier propre à Saint-Savin; notons toutefois que F'lorent y était honoré le 30 décembre, alors qu'il est généralement fêté le 22 septembre. Ils sont également mentionnés dans les calendriers de l'Église de Poitiers ${ }^{94}$, et dans ceux de Sainte-Croix de Poitiers et de Solignac ${ }^{95}$. Dom Estiennot a notén que dans plusieurs mss. de Limoges et de Solignac, Florent était fèté le 30 décembre comme à SaintSavin, et il cite d'après un bréviaire manuscrit de Saint-Savin l'oraison qui était récitée en l'abbaye à l'occasion de la fête des saints F'lorent, Romard et Prudence ${ }^{97}$.

L'inscription du dernier autel du déambulatoire ne peut être déchiffrée entièrement, car la partie antérieure de la table est dégradée depuis au moins le $\mathrm{xvir}^{\mathrm{e}} \mathrm{s}$. Iom Iistiennot a donné : Iste locus lulget in honorem IV coronatorum martyrum, dom Fonteneau n'a rien proposé mais a dressé un fac-similé un peu plus complet que ce que l'on observe aujourd'hui. Prosper Mérimée s'est borné à déclarer cette inscription "à peu près illisible ", tandis que I,onguemar commençait par suivre la transcription de dom I'onteneau : Iste locus fulget innocencinum, avant d'imaginer une très improbable date des calendes de mai r044. Enfin Ledain a cru pouvoir lire : Iste locus fulget in honore XLIIII virginum martyrum. La lecture in honorem ou in honore ne correspond pas aux fragments de lettres encore visibles, et il semble nécessaire d'écarter un patronage de quarantequatre vierges martyres, tant en raison du fait qu'elles sont inconnues par ailleurs que du patronage, celui-ci certain, de saint Romard pour ce même autel. On constate, en effet, que chaque autel est dédié à une certaine catégorie de saints, sur le modèle des litanies et des oflices liturgiquis, anges, vierges, confesseurs, martyrs, apotres : on n'aurait donc pas fait côtoyer sur le même autel des vierges et un martyr. Ia transcription de dom Fonteneau : innocen... a le mérite de correspondre à ce qu'on peut constater effectivement, mais la fin de cette partie antérieure de la table ne permet pas une lecture certaine. Ia proposition de lecture ci-dessous reste donc une hypothèse fragile, qui a surtout le sonci de stuivre le plus exactement possible les lettres ou fragments de lettres qui subsistent, et notanment un $a$ enclaré dans le $x$ :

92. Une lecture continue faisant d'Hermennitis un saint honore dans cet autel ne repose sur aucun fondement historique. Dom Fistiennot le reconnaissait en fait en avouant : "De suncto Hermenonio in altari $v$ quiescenti, nichil novi et de co silent hagiologia manuscripta " (B.X., lat. 12756 , p. 79$)$.

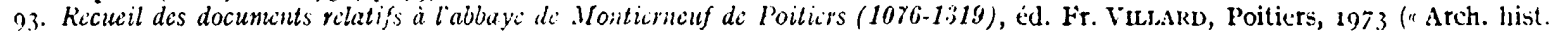
Poitou ", 59), p. 110 (chronique l.e coisstructionic moitasterii novi Pictuvis, par le moinc Martin).

9. Bibl. mun. Poitiers, ms. 40 , fol. 12 et 13 , début $x n^{\mathrm{e}} \mathrm{s}$; ms. 26 , fol. 3 vo et 5 vo.

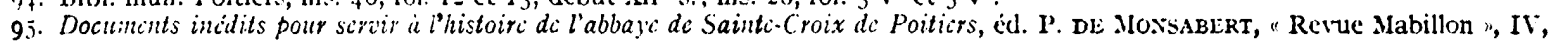

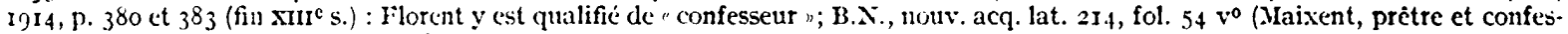
seur), fol. 82 (Florent, prêtre ct confesseur).

96. B..., lat. 12756 , p. 439 .

97. Ibid., n. 145: "Propitiarc, quacsumus Domine, famulis tuis, pro sancti confessoris tui Florentii, qui in nostra requiescit ccclesia, werita gloricsia, ut ejus pia intercessirme ab omnibus semper muniamur adversis. "Dom Estiennot ajoute : "Ilacc oratio dicebatur in festis $\leqslant$. Romardi et Prudentii. 


\section{ISTE LOCUS FULGET IN[NOC]EN[CIUM E]X ALIIS QUATUOR MARTIRUM.}

Dans la région on trouve encore, venant de Verrue, un reliquaire en plomb abritant Innocencium reliquie, et une châsse des saints Innocents figurait au trésor de l'abbaye Sainte-Croix de Poitiers en 1476 . On vénérait un des saints Innocents à Grandmont, deux à Saint-Eutrope de Saintes, trois à Saint-Jean-d'Angély et à la sainte chapelle de Bourges. Enfin on rapporte que Charlemagne aurait donné en 769 des reliques des Innocents à l'abbaye de Charroux, et que sous le règne de Pépin Ier d'Aquitaine un moine aurait apporté à Poitiers les corps de trois des saints Innocents ${ }^{98}$. Mais peut-être est-ce déjà aller trop loin, et sans doute serait-il plus sûr, comme l'a fait dom Fonteneau, de s'arrêter à ce qui peut être considéré comme probable : cet autel était placé en premier lieu sous le patronage des saints Innocents. Le second patron, inscrit sur la face latérale gauche :

\section{AC SANCTI ROMARDI MARTIRIS}

peut être identifié avec certitude. Saint Romard figure au calendrier des saints propre à Saint-Savin au I6 janvier comme confesseur non pontife, et un ancien bréviaire de l'abbaye déclare que le corps de Romard aurait été apporté de Châtelaillon à Saint-Savin au moment des invasions normandes ${ }^{99}$. Le prieuré de Saint-Romard est cité à Châtelaillon par les textes de la fin du XI $\mathrm{I}^{\mathrm{e}} \mathrm{s}$. au début du $\mathrm{XVII}^{\mathrm{e}} \mathrm{s}$., et aucune autre église du diocèse de Saintes n'est placée sous ce patronage ${ }^{100}$. Sous cette partie de l'inscription se trouvent des graffiti ne donnant aucun nom suivi sauf celui d'ODO. La fin de l'inscription, placée sur la face postérieure, n'est visible que depuis la remise en place de la table, mais la lecture qu'en a faite Ledain est paléographiquement erronée et doit être rectifiée. Au lieu de : Deus, miserere Emenoni. Posuit hoc Sismundus, il faut lire :

\section{DEUS MISERERE MEI EMENONI PER HOC SANCTUM MUNUS}

ce qui sera rapproché d'autres mentions de même ordre rencontrées dans les autels de Saint-Savin ${ }^{101}$. L'autel placé dans l'absidiole du croisillon sud du transept est le seul qui n'ait point été modifié par les bénédictins de la congrégation de Saint-Maur. Il est situé devant un sarcophage de pierre porté d'un côté par deux colonnes et scellé de l'autre dans le mur même, disposition proche de celle qui existait dans trois autres autels de Saint-Savin, qui deviendra surtout fréquente au $\mathrm{XII}^{\mathrm{e}} \mathrm{s}^{1{ }^{102}}$, mais qu'on observe dès le milieu du $\mathrm{IX}^{\mathbf{e}} \mathrm{s}$. au monastère de Fulda ${ }^{103}$. Ia fin du texte inscrit sur la face antérieure de la table a disparu :

\section{[ISTE ALT]ARIS POLLET SANCTORUM PETRI ET PAULI ET... \\ (face latérale droite) MISERERE TUIS ERMENONO GOFREDO GIRALDO \\ (face postérieure) JOSBERTO ME FECIT YSYMB[ERTUS]. \\ "Cet autel a pouvoir par saints Pierre et Paul et... Prends pitié des tiens, Ermenon, Geoffroi, Gérald, Josbert. Isembert m'a fait. "}

\footnotetext{
98. X. Barbier DE Montault, Euvres completes, t. X, Rome, VI. Hagiographie (2e part.), Poitiers, I895, p. 5 I7-535.

99. Inventio reliquiarum s. Marini, p. 486 .

100. Cartulaire de l'abbaye royale de Saint-Jean-d'Angély, éd. G. Musser, Saintes, I903 ("Arch. hist. Saintonge et Aunis ", 33), $\mathrm{n}^{0} 4 \mathrm{I}$, p. 78 (vers I098) : "In claustris Sancti Romardi, praesentibus monachis ipsius loci. "Abbé CholLET, Ménoire [sur les ruines de l'ancienne église du prieuré de Saint-Romuald], "Rec. actes Comm. arts et monum. de la Charente-Inférieure ", t. I, I86o/67, p. 2542, et G. M[CSSET], Saint-Romuald de Chatelaillon, "Rev. Comm. arts et monum. hist. de la Charente-Inférieure et Soc. archeol. de Saintes ", XVIII, I9I0, p. 213-214. Le passage de saint Romard à saint Romuald est dú au rattachement du prieuré à l'Ordre des Camaldules fondé par saint Romuald. Les documents eux-mêmes disent : "Saint-Romard. "

ror. Cf. fig. 5 .

102. RoHAUlt DE Fletry, La messe..., t. I, p. 203.

103. Vita b. Rabani Mauri archiepiscopi Mogtntini, A.A.SS., Février, I, p. 527 : "... Ossa beatae Caeceliae virginis et sanctorum martyrum Tiburtii et Valeriani intulit, atque in sarcophago saxeo post altare posuit."
} 
Il s'agit donc d'un autel dédié à saint Pierre et à saint Paul, et sans doute à tous les apôtres, sans second patronage local, situation identique à celle qui se présente dans l'autel qui lui fait pendant au croisillon nord. D'après les fragments de lettres qui subsistaient, dom Fonteneau a pensé que le nom de Barthélemy figurait à la fin de la face antérieure de la table.

L'inscription de l'autel du croisillon nord a été détruite, avec la table même, au début du xixe $\mathbf{s}$. I,e texte en est rapporté par dom Estiennot sous la forme suivante : Hoc altare consecratum est in honorem s. Michaelis et IX angelorum ordines et mon. Goffred. Dom Fonteneau n'a donné le fac-similé que d'، une seule ligne " de ce texte, comme il l'indique lui-même. C'est dire qu'il ne s'agit que de la face antérieure : + Hoc altare consecratus est in honore sancti Micahelis arcangeli + . Cette transcription en fac-similé montre la liberté que dom Estiennot prenait avec les textes, mais force nous est de nous fier à lui pour le reste de l'inscription puisqu'il en est le seul témoin. Compte tenu de ce que l'on constate dans les autres autels on proposera la disposition et l'état suivants :

\section{(face antérieure) + HOC ALTARE CONSECRATUS EST IN HONORE SANCTI MICA- HELIS ARCANGELI + \\ (face latérale droite) ET IX ANGELORUM ORDINES \\ (face postérieure) ERMON. GOFFRED. \\ "Cet autel a été consacré en l'honneur de l'archange saint Michel et des neuf légions d'anges. Ermon, Ceoffroi ${ }^{104}$. "}

Avec ce dernier autel on se retrouve à proximité du tombeau de l'abbé Odon. Mais le dossier épigraphique des autels de Saint-Savin ne s'arrête pas là. On ne sait à quel autel appartenait le fragment que l'abbé L,ebrun trouva parmi les décombres jetés dans l'escalier de la crypte de saint Marin et qu'il fit encastrer dans le mur de droite de cet escalier. Il s'agit du mot CONSECRATU, que l'on aurait volontiers attribué à l'autel de saint Michel dans le croisillon nord si le fac-similé de dom Fonteneau n'avait pas indiqué un enclavement du $A$ dans le $R$, ce qui oblige à écarter cette solution. En revanche on connaît une partie du texte inscrit sur l'autel matutinal de Saint-Savin grâce à un procès-verbal de visite de I64I que Mme Labande a récemment découvert dans les archives de l'abbaye ${ }^{105}$. L'autel matutinal était situé, dans les grandes églises monastiques ou cathédrales au fond de l'abside, et on y célébrait la première messe du matin ${ }^{106}$. Celui de Saint-Savin était accolé à une grande plateforme en pierre de taille (de sept pieds de long) sur laquelle on trouva un petit sarcophage de pierre (de trois pieds sur trois) et le couvercle d'un sarcophage double. Une inscription courait sur la face antérieure de la table d'autel et se terminait " du costé de l'Espittre ", c'est-à-dire sur la face latérale droite. A partir des lettres qui pouvaient encore être lues en $\mathrm{I} 64 \mathrm{I}$ on peut proposer la restitution suivante :

\section{HOC ALTARE NITET [IN HONORE] CHRISTI SALVATO[RIS]... [HER]MEN ME SCRIPSI[T]. \\ "Cet autel brille en l'honneur du Christ Sauveur... Hermen m'a écrit."}

Ce texte présente des analogies évidentes avec les autres textes des autels de Saint-Savin, tant dans le vocabulaire, la disposition, que pour le nom déjà cité à plusieurs reprises d'Hermen ou

\footnotetext{
10.4. Dom Fstiennot avoue : "De Goffredo monacho... non occurrit quidquam nec in hagiologiis nec in tabulariis " (B.N., lat. 12756, p. 78).

I05. X. Labavde-Marlfert, L'autel matutinal disparu de Saint-Savin-sur-Gartcmpe, "Cahiers civil. médiév. ", XVII, I974, p. 41-49. avec publ. de ce proceds-verbal.

106. D'après dom MLARTère, De antiquis ecclesiae ritibus, I, Rouen, I700, p. 306, le maître autel était souvent réservé aux grands dignitaires, le pape à Rome, l'évêque ailleurs, ou, dans les églises abbatiales, aux moines de l'abbaye; on célébrait les missas matutinales à un autel particulier.
} 
Hermenonius. S'il faut retenir avec un soin particulier cette consécration en l'homneur du Sauveur, on déplorera de ne plus avoir les noms qui devaient suivre sur cette face antérieure de la table. I a pierre a été rompue avec violence nous dit le procès-verbal sur une longueur de trois pieds environ, en divers endroits. Faut-il penser, comme le suggère à titre d'hypothèse Mme I abande, que cet autel pouvait abriter les corps des saints Savin et Cyprien? Il faudrait alors entendre le mot " corps" dans le sens large de "reliques", car on sait que depuis le début du $\mathrm{x}^{\mathrm{e}} \mathrm{s}$. le corps de Cyprien reposait en l'abbaye de Saint-Cyprien sous les murs de Poitiers. Il n'est possible de rien affirmer, tout comme, dans l'état de nos connaissances, nous devons nous résigner à tout ignorer du grand autel de l'église abbatiale.

Il subsiste un nombre suffisamment élevé d'inscriptions d'autels pour qu'on puisse penser que les prescriptions de la fin du XIrre et du début du XIV ${ }^{\mathrm{e}}$ s. n'ont fait que confirmer une tradition ancienne. En effet Guillaume Durand recommande dans son Pontifical de placer avec les reliques, la veille de la consécration de l'autel, " une charte en parchemin, écrite en grosse lettre, contenant l'état des reliques placées dans l'autel, le nom du saint en l'honneur duquel l'église et l'autel sont dédiés, le nom du prélat consécrateur, l'indulgence accordée au jour de la dédicace, la date précise de cette dédicace ${ }^{\mathbf{1 0 7}}$ ), et le concile de Trèves de I3Io ordonne que dans chaque église il y ait, devant, derrière ou sur l'autel, quelque sculpture, inscription ou peinture indiquant en l'honneur de quel saint l'autel est construit ${ }^{108}$. Mais, pour autant qu'on puisse en juger à partir d'une recherche portant sur une quarantaine d'inscriptions d'autels, le formulaire de ces inscriptions n'est pas encore, jusqu'au milieu du xI ${ }^{\mathrm{e}} \mathrm{s}$., fixé dans l'expression qui va alors devenir habituelle : consecratum est hoc altare in honore... ${ }^{109}$, et qui ne se rencontre à Saint-Savin que dans un seul autel. Il faudra naturellement une recherche attentive du formulaire, en ce domaine comme en beaucoup d'autres, pour pouvoir en mieux cerner l'évolution chronologique.

I a langue de ces inscriptions reste marquée par un vocabulaire de type carolingien, tandis que la grammaire témoigne d'une décadence du latin classique fréquente dans les textes du $\mathrm{x}^{\mathrm{e}}$ et du début $d u x I^{e}$ s. Ainsi dans les vers qu'ils réservent à des inscriptions d'autels, Alcuin emploie généralement des verbes tels que fulget, ornet, micat, servet, tenet, exornat ${ }^{110}$, et Raban Maur les formes fulget, refulget, pollet, ornet, tenet ${ }^{111}$. De même on trouve chez l'un comme chez l'autre l'inversion Baptista Johannes qui figure dans l'autel de la chapelle axiale à Saint-Savin ${ }^{12}$, ou l'expression de l'autel des confesseurs, hac... sacra veneratur in ara, hac... veneralur in ara, hac... sacra venerabilur ara ${ }^{113}$. Le verbe polleve se rencontre aussi dans une inscription de dédicace d'église à Séville en $622^{114}$. D'autre part le neutre altare est à deux reprises transformé eil un masculin altaris, et lorsqu'il est employé au neutre dans l'autel du croisillon nord il est aussitôt suivi de consecratus est. Sur cette même table d'autel on a in honore... angelorum ordines, ct de même, après

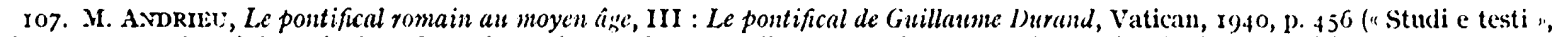
88) : "Ponat etiam ibi carticulam de corio, scriptam de grossa littera, continentem cujusmodi reliquic sunt ibi incluse, et in cujus sancti houorem et nomen ecclesia ipsa et altare dedicantur, nomen consecratoris et indulgentiam quam in anniversario dedicationis die concedit, annum quoque, mensem et dien quibus dedicatur...".

108. Dom Makrive et dom Durawd, Thesaurus novus anecdotorum, t. IV, Paris, I7 7 , col. 25.4, \$69: "Praecipimus ut in unaquaque cclesia ante vel post vel super altare fiat inago vel sculptura vel scriptura expresse designans et cuilibet intuenti manifestans in cujus sancti meritum et honorem sit ipsum altare constructum. "

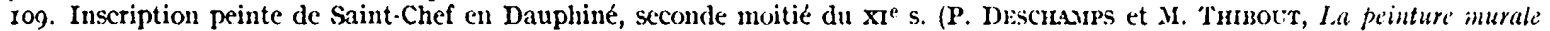
en France. Le hazt moyen ase et l'époque romane, Paris, 195I, p. 49-50 (t pl. XII, 2); autel de l'église Santa Maria in Portico à Rome en 1073 (M. Akurdurvi, Le chiese di Roma dal secolo IV al XIX, Rome, 2 éd., 1891, p. 629); inscriptions des autels de Montierneuf

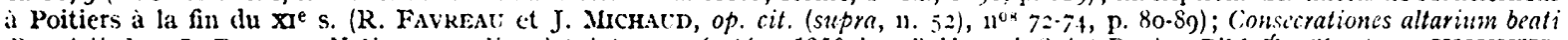

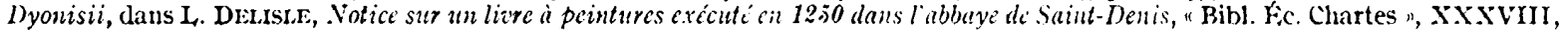
1877, D. 463.466 , etc.

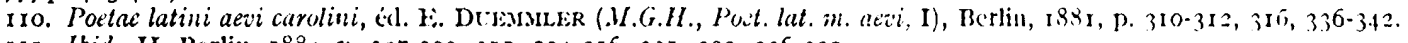

111. Ibid., II, Berlin, 1884, 1). 207-209, $211,214 \cdot 216,2.21,223,226 \cdot 231$.

I12. Ibid., I, p. 312, 315, 333, 336, 339, 347 (Alcuin); II, p. 230 (Raban Maur)

I13. Ibid., I, p. 314, 3 II (Alcuin); II, p. 21 I (Raban Maur).

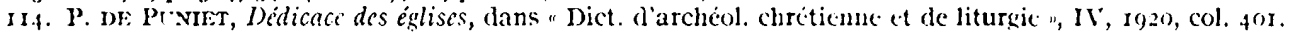


le in honore sanctarım du premier autel du déambulatoire au nord, les noms des rierges sont donnés au nominatif. Dans l'autel suivant cum Clemente... atque . Mauricio est suivi d'un génitif, et omnium martirum. Après le fulget de l'autel de saint Romard et le pollet de l'autel des apôtres on rencontre immédiatement un génitif. On peut rapprocher ce très médiocre latin de celui d'une inscription de dédicace à Saint-Michel de Montflans en 972, haec aula qui est fundala in vila ${ }^{\mathbf{1 1}}$, et de celui d'une inscription de consécration d'autel à Pontlevoy en $1035 / 60^{116}$. I à aussi l'existence d'un vers dans le texte de l'autel de la chapelle axiale peut être considérée comme le témoignage d'un passage proche à une bien meilleure connaissance du latin.

Passons à l'étude paléographique. I'abondance des conjonctions, enclavements, entrelacements, l'irrégularité et la rareté de la ponctuation, l'abondance des formes carrées, c'est-à-dire des droites remplaçant les courbes, dans les lettres $C$ et $G$, le très petit nombre des onciales, amènent à placer ces textes dans la première moitié du $\mathrm{xI}^{\mathrm{e}} \mathrm{s}$. On peut même ajouter, mais il faudra une étude plus développée pour préciser cet aspect, que certaines conjonctions, notamment celle par superposition des deux premières lettres de Georgio, se trouvent surtout dans les inscriptions de l'Espagne. Ainsi l'analyse de ces inscriptions confirme la date que suggéraient les sources narratives, c'est-à-dire la première moitié du $\mathrm{xI}^{\mathrm{e}} \mathrm{s}$., au temps de l'abbé Odon ${ }^{117}$.

On peut aussi considérer dans leur ensemble la trentaine de noms de personnes autres que les saints, inscrits sur les autels, pour moitié gravés en capitales à l'égal du texte principal, pour moitié tracés en écriture cursive et de façon si discrète qu'ils avaient jusque-là échappé aux nombreux historiens de l'art qui ont étudié l'église de Saint-Savin. Ils ont un point commun, qui explique d'ailleurs qu'on ne leur ait prêté qu'une médiocre attention : ils sont situés sur la face postérieure, sur la face latérale droite, et, une fois seulement, sur la face latérale gauche des tables d'autel. Dans les absidioles du déambulatoire, à l'exception de l'absidiole axiale, il est très difficile de faire le tour des autels. Ce fait, et l'absence de graffiti sur le devant et sur la partie supérieure des tables d'autel, exclut, me semble-t-il, qu'il puisse s'agir de noms de pèlerins ou de pieux visiteurs. Plus probablement, on peut y voir des noms de donateurs, de moines ou d'ouvriers de l'époque de la construction, comme nous y invitent les quatre expressions suivantes : Detts, miserere mei Emenoni per hoc sanctum munus, miserere tuis, me fecit Ysymbertus, Hermen me scripsit. On observera par ailleurs que dans les noms fortement gravés le nom d'Hermenonius ou Ermenonius apparait six fois, celui d'Ysymbertus deux fois, de même que dans les graffiti on trouve à deux reprises les nows d'Odo, Stephanus, 'Tetberga, avec la certitude, pour les deux derniers, qu'il s'agit bien d'une même signature. Ce n'est sans doute pas trop s'avancer que de penser qu'Isembert est l'auteur des tables et qu'Hermenon a écrit les inscriptions, tandis que les autres noms appartiennent sans doute à ceux qui participèrent d'une manière quelconque à la construction de ces autels. Ces noms auraient alors été gravés pour implorer, pour ceux qui les portaient, la miséricorde de Dieu, à la manière d'un memento, Domine, formule que l'on retrouve d'ailleurs dans diverses inscriptions ${ }^{118}$.

115. P. Discumps, litude sur la paliographie des inscriptions lapidaites de la fin de l'époque mérovingionne aux dernieres anués du $1^{*} l^{\mathrm{e}}$ siecle, "Bull. monum. "I,XXXVIII, 1929, p. I9 et fig. I 2

116. "In onore sancte Jonnis Bactiste iste altare sacratus est in tempore Ausberti primi abbati. Adenor femina fieri jussit in tenpore Il.rrico rex " ("Rev. Soc. sav. départements ", 50 s., V, 1872, p. 475-476).

17. P. 1)rscramps, Etude..., donne comme date pour l'écriture de ces inscriptions soit le milicu du xi s. (p. 77 ), soit plus généra l.ment la seconde moitié du xie s. (p. 23, 73, 79).

11. Pierre d'autel à chrisme a Chambornay-les-Bellevaux (IIaute-Saône) portant autour du chrisne : " Apostuli et martyres, mementote nostri in conspectu Domini "; porte de bronze de la cathédrale de Ravello en 1 I 79 : "Memento, Domine, famulo tuo Sergi Mussetule et uxori sue Sicligaude et filiis suis Mauro et Johannes et filia sua quot ista porta facere agit ", et également : Memento, Domine, famuli tui Scrgi Mussetule de Jordane "A. BoEcklek, Die Bronzetüren des Bonanus ion Pisa und des Barisanus a'on Trani, Berlin, 1953, p. 47.49, fig. Ioo et 1 I I ( Frühmittelalterlichen Bronzctüren ", 4]). Mais le rapprochement le plus saisissant qui puisse Ctre fait est celui de ces inscriptions de Saint-Savin avec celle qui fut trouvée dans le tombeau de saint Martial à Limoges, et date sans doute du concile de Limoges de 1031 au cours duquel fut vivement discutce l'apostolicité de: Martial. Sur la pierre on lisait :

HIC REQUIISSCIT CORPCS BEATI MARTIALIS DISCIPLI, ET APOSTOI, CHRISTI JISSS, et sur l'épaisseur de la pierre

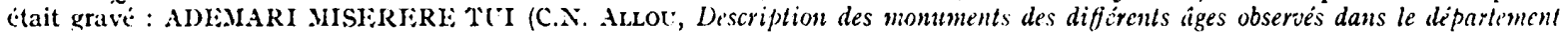

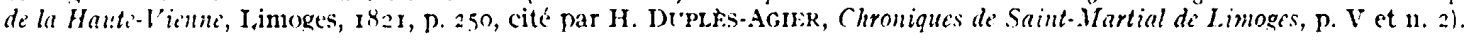


Une étude des noms de personnes employés dans la région fournirait peut-être des enseignements sur l'évolution chronologique de leur emploi'119, mais il est regrettable ici de ne pouvoir disposer de sources diplomatiques concernant l'abbaye même. I a pratique de l'inscription de noms sur les tables d'autel n'est pas propre aux premiers temps du moyen âge. Sur la face postérieure et les deux faces latérales de la base d'un autel à Moissac, comme il a déjà été dit, on a trouvé une série de graffiti comportant principalement des noms gravés au $\mathrm{IX}^{\mathrm{e}} \mathrm{s} .{ }^{120}$, et on peut citer la présence de graffiti sur des tables d'autel à Planés en Catalogne ${ }^{121}$, à Saint-Féliu d'Amont en Roussillon ${ }^{122}$, à Tonquières dans le Gard ${ }^{123}$. Il n'est pas inutile de souligner encore l'intérêt exceptionnel de cette conservation, à Saint-Savin, de six des autels romans. Il est sans doute bien peu d'églises construites à cette époque où l'on puisse retrouver un tel ensemble.

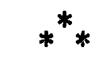

En I64I, lors de la visite de l'église abbatiale, le sénéchal de Saint-Savin nota, dans la crypte principale, un autel à l'arrière duquel il y avait " ung cerceuil de pierre joignant immédiatement ", à l'avant duquel étaient écrits les mots : Requiescit santissima Savina virgo ${ }^{124}$. Dom Martène et dom Durand au début du Xvirre $s$. virent l'autel de la crypte, le sépulcre joignant l'autel, et relevèrent l'inscription, à l'exception de la dernière ligne, couverte par la pierre. Ie sarcophage est toujours en place, si ce n'est qu'il n'est plus engagé dans l'autel. L'inscription peut être lue aisément :

\section{HIC REQUIESCIT SANCTISSIMA SAVINA VIRGO †}

Ce texte, un peu plus soigné que la majorité des textes des autels, offre trop de ressemblances avec ceux-ci pour s'en écarter beaucoup au point de vue de la datation ${ }^{125}$. Il s'agit évidemment de la sainte Savine nommée sur l'autel des vierges dans une des chapelles du déambulatoire. Le calendrier de Saint-Savin la cite au I 5 juillet comme " vierge et martyre ", et un bréviaire de 1'abbaye de la Trinité de Poitiers la mentionne également à cette date ${ }^{126}$. Mais d'où venait-elle? Qui était-elle? Dom Chamard a écrit que son corps avait probablement été apporté à Saint-Savin " au $\mathrm{Ix}^{\mathrm{e}} \mathrm{s}$. avec les nombreuses reliques du Bas-Poitou ${ }^{127}$ ". Aucun document ne vient à l'appui de cette hypothèse. Le père Baudouin de Gaiffier a noté que la Passion de saint Savinien de Troyes, qui est une des sources de la Passion des saints Savin et Cyprien, attribuait à Savinien une sœur sainte Sabine ou Savine ${ }^{128}$. Cette dernière était fêtée le 29 janvier, comme saint Savinien, et à Saint-Savin les moines fêtaient successivement saint Savin le II juillet, saint Cyprien le I4, sainte Savine le I5.

I19. G.T. BEFCH a donné une première étude générale sur Les noms de personne poitevins du $1 X^{\mathrm{e}}$ au $X I I^{\mathrm{e}} s$. ("Rev. intern. d'onomastique ", XXVI, 1974, p. 81-100), et il annonce une étude des noms individuels. D'après son tableau II, la plus grande fréquence du prénom Bernardus se situe entre 975 et 1025, celle du prénom Stephanus de 1025 à 1050. Beech note l'avance des noms chrétiens dés le $\mathrm{x}^{0} \mathrm{~s}$. Or les noms relevés sur les autels sont presque tous germaniques.

120. Cf. supra, n. 62 .

121. L'art roman [catalogue de l'exposition de Barcelone et Saint-Jacques-de-Compostelle], 196r, p. 140.

122. L. DE BonNeroy, Epigraphie roussillonnaise, ou recueil des inscriptions des Pyrénées-Orientales, Perpignau, $1856 / 60, \mathrm{p}$. 134.

123. H. RevoII, Architecture romane du midi de la France, Paris, 1874, t. II, p. 21-22.

124. Y. LABANDB-MLARERT, L'autel matutinal..., p. 49.

125. Méme forme du premier $C$, du $G$, méme enclavement du $l$ dans le $V$. Dom F. Chasard (Origines de l'Eglise de Poitiers, Poitiers,

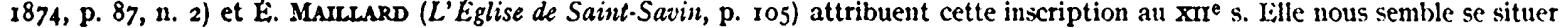
entre celles des autels et celles des peintures de la crypte. Cf. pl. III, I.

126. V. LeROQUaIs, Les pontificaux manuscrits des bibliothèques publiques di France, Paris, t. I, 1937, n 247, p. 452

127. Dom F. Crascaro, op. cit., p. 87, n. 2.

128. B. DE GAIrfure, Les sources de la Passion des saints Savin et Cyprien, "Analecta Bollandiana ", LXXIII, I955, p. 333-334, n. 3. Sainte Savine est fêtée à Troyes le 29 janvier et mentionnéc dans de nombreux bréviaires de cette région. 


\section{Illustration non autorisée à la diffusion}

Fig. I. SAIN'T-SAIIN-SI R-CiAR'TISIPI: (V'ienne). Autcl de la deuxieme absidiole nord du deambulatoire. Fac: antéricure. Début de l'inscription.

\section{Illustration non autorisée à la diffusion}

lïg. 2. Id. Fin de l'inscription.

\section{Illustration non autorisée à la diffusion}

Irig. 3. Id. Citć droit. listampage.

\section{Illustration non autorisée à la diffusion}

lïg. +. Id. Cinç gauche. Istampage. 


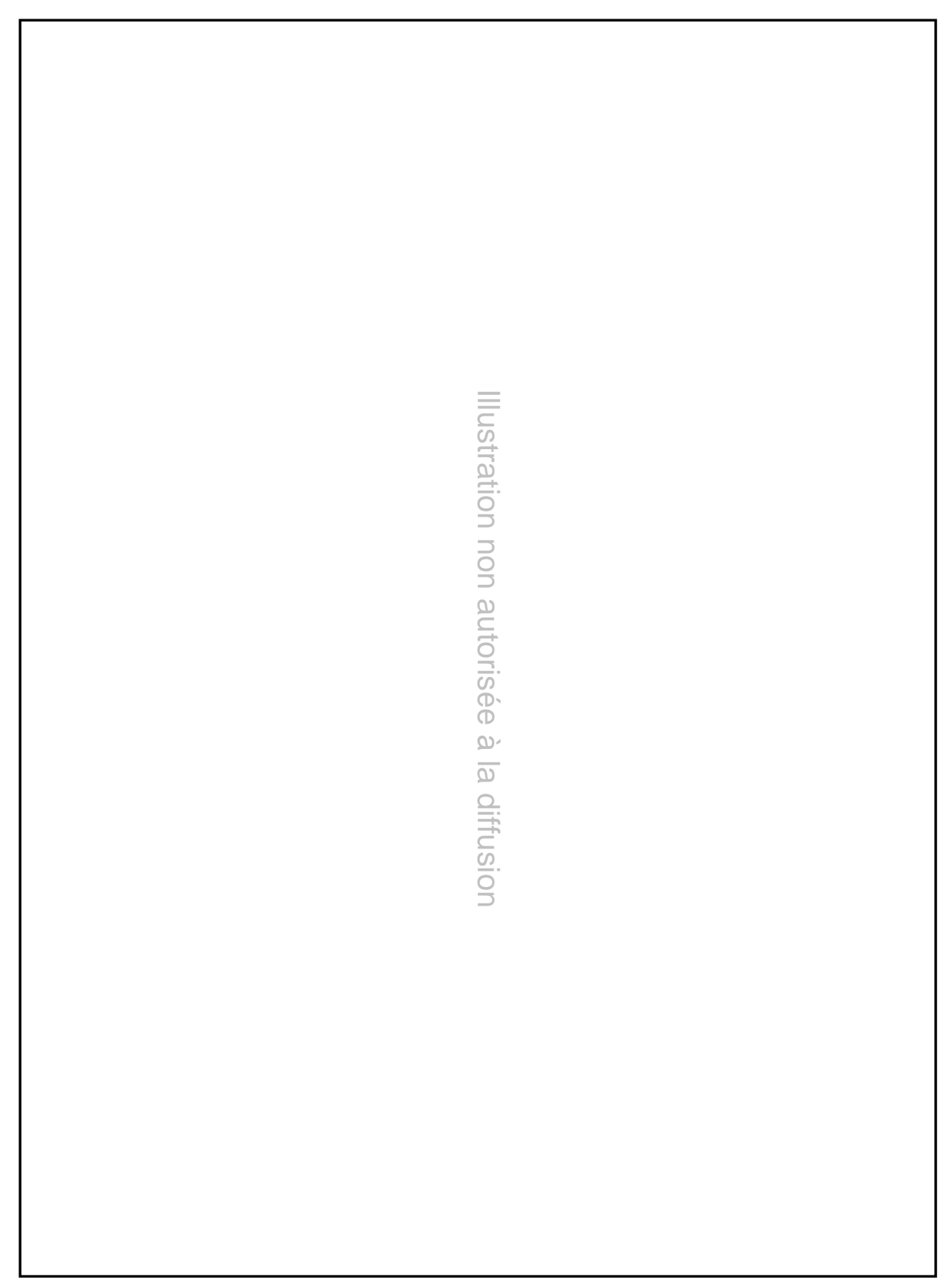

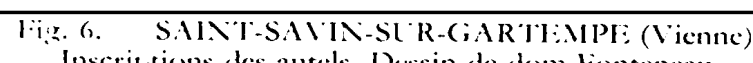

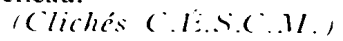

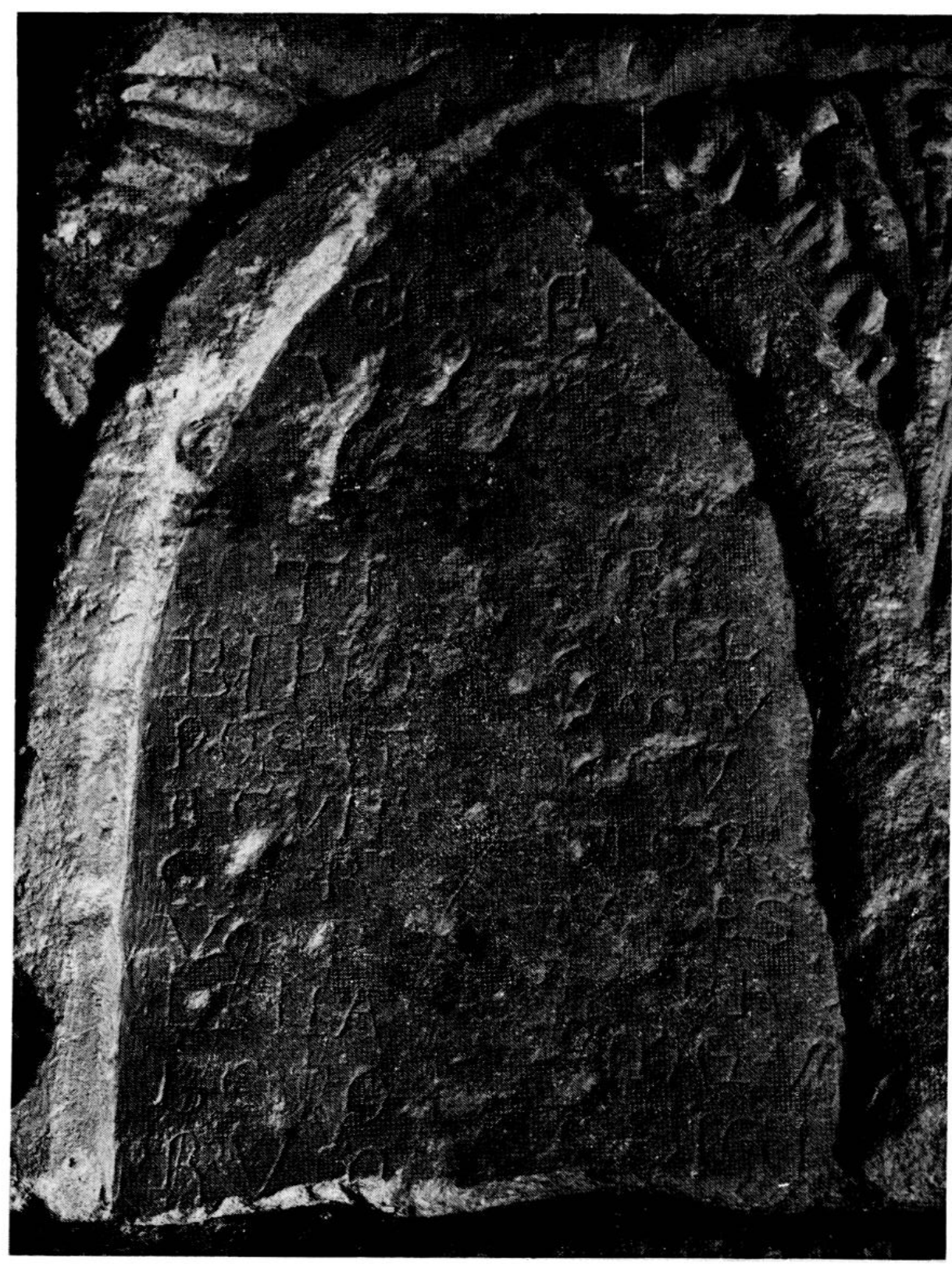

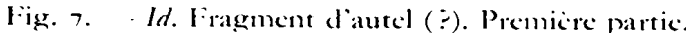




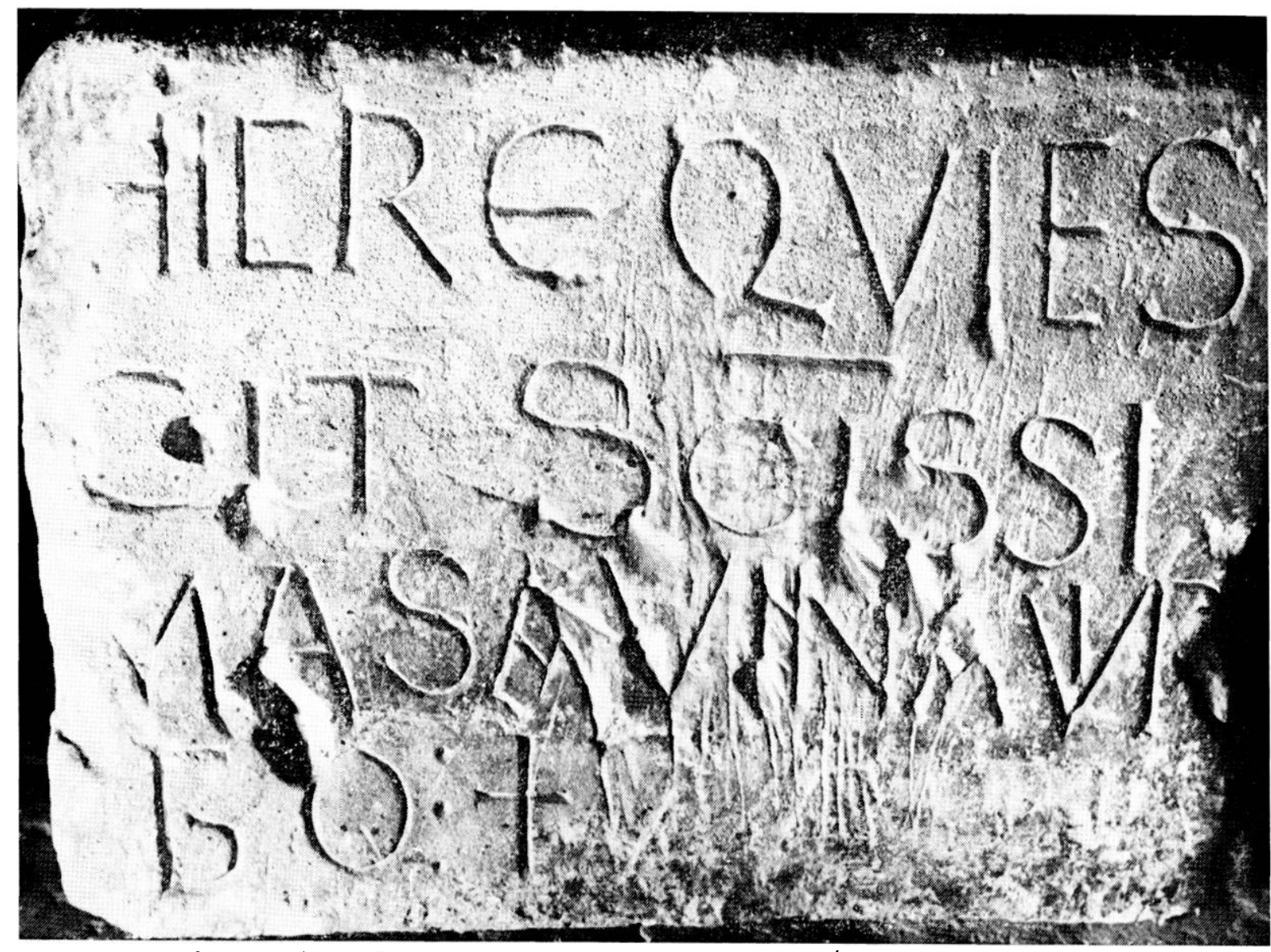

IḦg. 8. SAINT-SAVIN-SLR-(BARTEMPPE (Vienne). Crypte. Epitaphe de sainte Savine. 


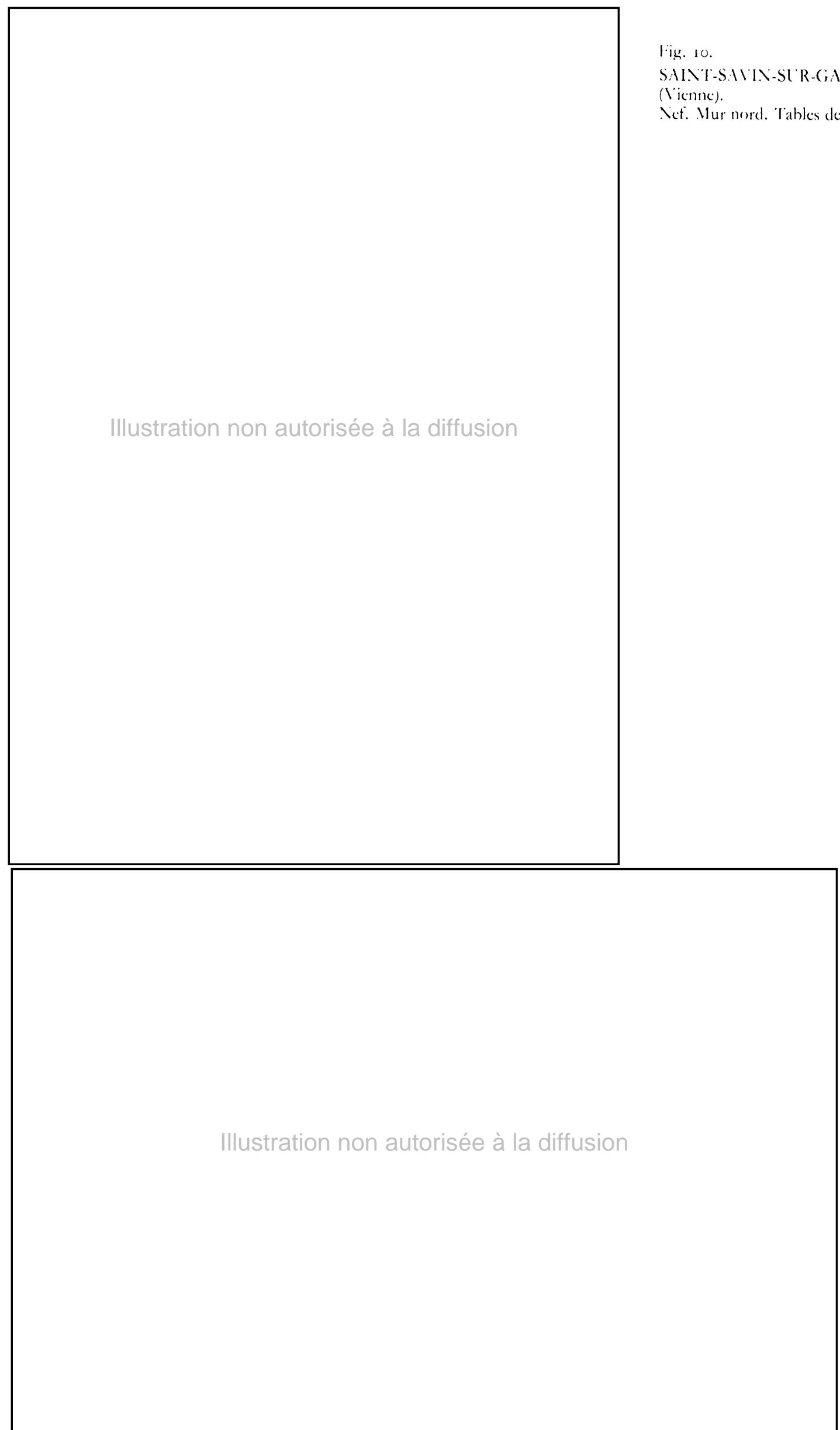


Tout un ensemble peint entoure l'autel et le sarcophage de sainte Savine : au-dessus de l'autel le Christ en majesté, encadré des symboles des quatre évangélistes, sur les murs nord, est et sud, huit saints et saintes qui portent chacun une couronne. Cet ensemble est beaucoup moins connu que la légende des saints Savin et Cyprien peinte dans le reste de la crypte. Il est pourtant d'un grand intérêt, car il montre la liaison parfaite qui a été établie entre les inscriptions des autels et les peintures de la crypte. L'élément central autour duquel s'organisent les figures est constitué par le Christ entouré d'une gloire dans laquelle est peinte une inscription en deux hexamètres léonins qui n'a jamais été relevée ${ }^{129}$. La majeure partie en subsiste encore aujourd'hui :

DAT SANCTIS DIGN[AS] ............. SORTE CORONAS ..IT... US JUDEX MERITORUM SPLENDIDUS INDEX.

La nécessité d'une rime à l'hémistiche permet de lire avec certitude DIGNAS au premier vers. En fonction de la métrique diverses restitutions peuvent être proposées, par exemple :

Dat sanctis dignas mirabili sorte coronas

Sit clarus judex meritorum splendidus index.

Le sens lui-même est évident : le Christ donne aux saints les couronnes qu'ils ont méritées; il est le juge des mérites, Lui qui en est le remarquable guide. Cette inscription peut être rapprochée de celle du célèbre tympan d'Autun : Omnia dispono solus, meritosque corono, et l'expression de judex meritorum figure sur un reliquaire du trésor de la cathédrale de Cologne ${ }^{130}$. Tout naturellement chacun des évangélistes était accompagné de son nom, et on lit encore très bien celui de LUCAS. Enfin les couronnes annoncées par l'inscription se trouvent aux mains des huit saints et saintes représentés ici.

L'identité de deux de ces saints est bien connue, car leurs noms, peints de chaque côté de leurs têtes, ont été notés par Mérimée et sont encore partiellement lisibles. A gauche (pour le spectateur) de la baie qui s'ouvre au milieu du mur est on trouve S. ou sans doute SCS PRUDEN[CI]VS, à droite S. FER [CINCTA]. Un examen attentif, avec un éclairage adéquat, a permis d'identifier avec certitude les deux saints situés au centre des murs nord et sud. Pour le premier son nom se lit entièrement, à gauche (pour le spectateur), horizontalement $\overline{S C S}$, puis verticalement SAVINUS, pour le deuxième son nom est peint verticalement et à droite, les trois premières et les quatre dernières lettres, celles-ci les plus visibles, étant sur une même ligne : FLOOR]ENTIUS. Il semble, en outre, qu'à la droite de saint Savin figure sainte Savine, tant en raison de traces de lettres que du fait que c'est la seule sainte ici représentée avec Fercincte, et qu'à la gauche de Florent se trouve saint Marin, si les quelques lettres ou fragments de lettres à peine visibles près du personnage sont bien interprétés. Pour les deux derniers saints, il faut certainement penser à saint Romard et assez probablement à saint Maixent. Ainsi aurait-on la représentation dans la crypte de tous les saints dont les reliques étaient effectivement vénérées dans les autels du déambulatoire et sans doute du chœur. Une inscription courait sous les huit saints, dans une bande de couleur sombre. Seules quelques lettres en subsistent, aux pieds de sainte Fercincte :

\section{HIC DEN[SUS] E[ST] CONF[E]SSO[RUM CETUS].}

129. E. MaIllakd, op. cit., p. 98 , dit que ces vers ne sont "plus déchiffrables ". Dans sa thise De versu leonino (Lyon, 193I) J. Des.

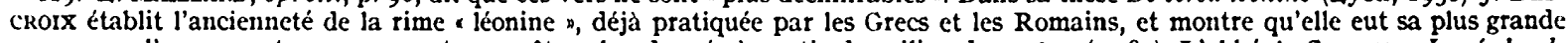
vogue vers l'an 1100 et un peu avant, pour être abandonnée à partir du milieu du XII ${ }^{e} \mathrm{~s}$. (p. 82). I'abbé A. CLERval, Les écoles de Chartres au moyen age (du $V^{\mathrm{e}}$ au XVI siecle), Paris, 1895, p. I12, écrit à propos de Fulbert de Chartres : « La rime... règne absolument dans le nouveau système de versification rythmé, et le pénètrera de plus en plus, jusqu'a produire franchement la rime tiche sur la fin du $\mathrm{XI}^{\mathrm{e}}$ sickle. Cf. figure 9 .

130. F.X. Kraus, Die christlichen Inschriften..., p. 255 : "Quos tulit ille dolens, qui judex est meritorum." 
I, es restitutions proposées ne représentent qu'une hypothèse en fonction du sens, et on serait plus à l'aise si l'on pouvait s'appuyer sur la métrique comme pour les autres textes de la crypte. Plusieurs inscriptions de la Rhénanie du $\mathrm{x}^{\mathrm{e}}$ et du début du $\mathrm{XII}^{\mathrm{e}} \mathrm{s}$. emploient le terme de cetus dans un contexte comparable, notamment celle de la grande couronne de lumière offerte à son église de Weissenburg par l'abbé Samuel ( $†$ I074) où sont cités les élus qui se présentent devant le trône du Christ avec leurs couronnes ${ }^{131}$.

I,es inscriptions qui accompagnent la Passio des saints Savin et Cyprien sont, elles, bien connues grâce aux multiples reproductions qui ont été données de ces peintures. Il est, du point de vue de l'historien de l'art et de l'épigraphiste, de médiocre importance que la Passio qui a servi de modèle au peintre ait été compilée à partir de la Passion latine de saint Mocius, martyr, patron de Constantinople, de la Vie de saint Germain d'Auxerre, de la Passion de saint Savinien de 'Troyes, sources auxquelles on aurait ajouté l'existence d'un frère de Savin, Cyprien ${ }^{132}$. L,es moines ont cru à sa réalité historique, elle a servi de base au peintre, elle a nourri pendant des siècles la foi de ceux qui venaient visiter la crypte de l'abbatiale. La fête de saint Savin est citée déjà dans le Martyrologe d'Usuard, c'est-à-dire au $\mathrm{IX}^{\mathrm{e}}$ s., ainsi que dans une trentaine de bréviaires, missels, pontificaux ou sacramentaires du Poitou, du Limousin et des régions voisines, dont les plus anciens remontent au $\mathrm{xI}^{\mathrm{e}} \mathrm{s} \cdot{ }^{133}$. Mais on ignore à quelle date a été composée la Passio, dont on sait seulement qu'elle est dépourvue de tout fondement historique.

Les inscriptions qui accompagnent la représentation légendaire du martyre de Savin et de Cyprien sont de deux sortes. Les unes, placées dans le champ des scènes, permettent l'identification des personnages, I,ADICIUS, SAVINUS, CIPRIANUS au mur nord, MAXIMUS, SAVINUS et CIPRIANUS au mur sud. Filles sont parfaitement conservées, et sont tracées tantôt verticalement, tantôt horizontalement. Savin est toujours placé devant Cyprien, et son nom est cité une fois de plus. I,es autres textes sont peints en lettres blanches dans les bandes de couleur sombre qui soulignent les deux registres de chacune des parois. I,es seuls où il soit possible de lire quelques mots se trouvent dans les bandes supérieures. On lit au mur nord, au plus près de l'autel :

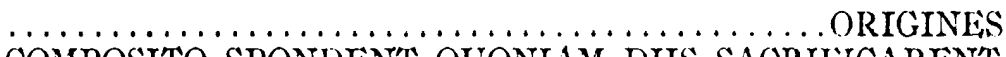

COMPOSITO SPONIFENT QUONIAM DIIS SACRIFICARENT,

et au mur sud, en la partie médiane de la bande :

Au mur sud où le texte est le mieux conservé, il est évident qu'il y a eu, à la bande supérieure, trois hexamètres léonins, ce qui laisse supposer que douze vers accompagnaient la légende de Savin et de Cyprien, pour commenter les différentes scènes représentées. Quant aux autres lettres actuellement encore visibles, peut-être les progrès techniques en permettront-ils une lecture plus complète, mais elles ne peuvent guère actuellement être utiles que pour l'analyse paléographique.

I'exanen de l'écriture montre qu'il y a une nette évolution entre les inscriptions des autels at celles de la crypte. Ici les inscriptions sont tracées avec une grande régularité, les lettres ont une

\footnotetext{
131. Ibid., $\mathrm{n}^{0}$ 132, p. 59 (Weissonburs); $\mathrm{n}^{0}$ 146, p. 6,3 (Spire); $11^{0} .491$, p. 2.31 (Aix).

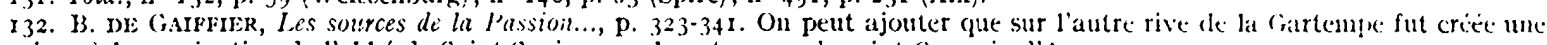
paroisse, a la nomination de l'abbé de Siant-Savin, sous le patronage de saint ciermain d'Auxerre.

133. Cf. les onvrages du chan. Ieroquais, complétés par cies recherches pour les églises poitevines. Sur 32 montions, deux concernent

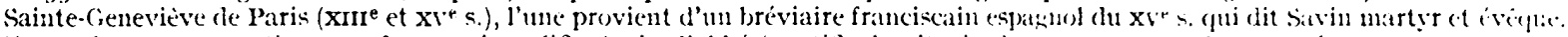

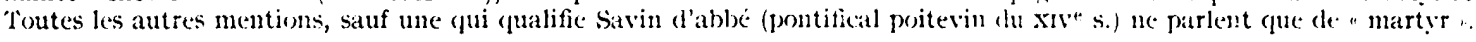


forme soignée, sont parfaitement arrondies, les abréviations sont rares, il n'y a pas, autant qu'on puisse en juger, de conjonctions ni d'entrelacements, et les rares enclavements ne sont pas de nature it nuire à la clarté. I.es formes carrées ont complètement disparu, alors que dans les autels on avait un $(i$ classique pour sept ( $i$ carrés, quinze $C$ classiques pour dix-neuf $C$ carrés. Contrepartie logique, le nombre des onciales progresse. Dans les autels, sur cinquante-cinq $E$ quatre étaient onciaux, dans la crypte il $y$ a aussi quatre $E$ onciaux. mais sur dix-sept $E$; dans les autels on avait une onciale sur vingt et un $W$ et sur vingt-cinq $T$, tandis que dans la crypte il y a deux $M$ onciaux sur huit, deux $D$ onciaux sur neuf, mais aucun $T$ oncial. Quant au latin il est ici d'excellente qualité, et l'emploi du vers léoiuin témoigne évidemment d'une plus grande maîtrise de la langue qui contraste avec la médiocrité de la forme dans les inscriptions des autels. On doit noter la présence d'une diphtongue.

I,e dossier épigraphique permet donc deux conclusions générales. D'abord il amène à constater une parfaite correspondance entre les autels du déambulatoire - et sans doute du chour, - et les peintures de la crypte. Les inscriptions offrent ici une remarquable illustration de ce que représentait le culte des saints à Saint-Savin et montrent combien est étroit le lien entre épigraphie et liturgie. Fin second lieu il oblige à considérer que les inscriptions de la crypte sont nettement postérieures à celles des autels, différence qu'on peut estimer de l'ordre du demi-siècle.

De la même époque que les inscriptions de la crypte sont probablement celles qui accompagnent les grandes figures d'évêques peintes dans le chœur, au nombre de huit, en deux registres, sur les faces nord-est et sud-est des piliers du transept. Il s'agit des noms de ces évêques, peints à leurs pieds dans des bandes rouges, mais seul celui de Fortunat, l'évêque du registre supérieur au plus près du côté sud du déambulatoire, peut être aujourd'hui lu avec certitude, sous la forme : SCS FORTUN[ATUS]. Quelques lettres subsistent également pour l'évêque situé de même façon du côté nord : .....ER(ou P)US EPISCOPUS, ce qui est insuffisant pour une identification, Liberius, Fauzbertus, Froterius?, s'il s'agit bien, comme il est vraisemblable, d'évêques de Poitiers. On trouvait de même la suite des évêques de Poitiers peints en grands portraits monumentaux sur les piliers de la nef de Saint-Hilaire-le-Grand ${ }^{134}$, et il faut aussi noter dès maintenant qu'ils figurent également dans la tribune de Saint-Savin. Bien qu'ils soient anépigraphes, on doit encore signaler la présence, à la base diu cul-de-four, de figures de saints en pied ou en buste, l'un d'entre eux portant une couronne comme dans la crypte.

Ouelle est donc la situation à Saint-Savin un demi-siècle apris l'abbé Odon? Il était cité pour la dernière fois en 1040, et à sa suite, à une date et pour une durée incertaines, l'abbaye fut dirigéc par un abbé indigne, sous lequel la règle fut si mal observée que la discipline fut abandonnée, laissant place à tous les désordres ${ }^{135}$. Ce fut sans doute cet abbé que, en I079 ou ro8o, le légat Amat d'Oloron convainquit en plein chapitre monastique de simonie; au lieu d'obéir au légat et de se rendre devant l'évêque de Poitiers, l'abbé s'empara de quelques reliques et ornements de son église et s'enfuit ${ }^{136}$. Un moine de Saint-Cyprien, Gervais, homme remarquable par ses vertus, fut alors appelé à réformer l'abbaye, mais il fallut toute l'insistance de l'abbé de Saint-Cyprien,

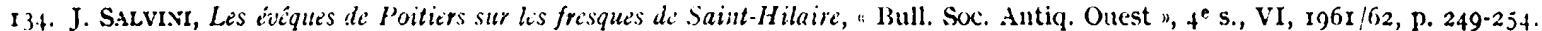
135. A.t.SS., Avril, II, p. 225, vie de Bernard de Tiron : ".. Quia per praecedentis abbatis negligentiam, loci illius congregatio regularis vitae tramitem deseruerat, et rigorem disciplinae in teporem vitae ac dissolutionem commutaverat."

136. Voir lat lettre que le légat écrivit à ce sujet à l'archevéque de Tours dans $H . F .$, XIV, 67o. Fille est généralement datée de ro8o

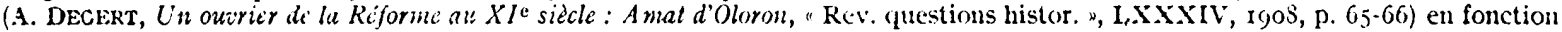
du concile de Bordeaux dont elle fait étut. Fin fait les historiens discutent sur la guestion de savoir s'il y a eu alors un seul concile à

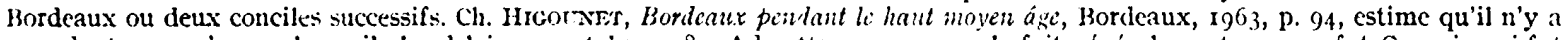
sans doute eu qu'un seul concile bordelais, en octobre roso. Adnettre, comme on le fait généralement, que ce fut Gervais qui fut convaincu de simonie en ro8o par le légat et qui prit alors la fuite, c'est se tronver en contradiction absolue avec les autres textes relatifs à rervais. Ou bien il faut reconsiderer les dates des conciles de Poitiers (selon les historiens ro78 on 1079, voire 1078 et 1079) ct de Bordeaux ( 1079 et ro8o ou ro8o seuicment), ou bien il faut placer le premier acte ou apparaît (;ervais (cf. infra, 11. I 39) au début de 
Rainaud, pour qu'il acceptât cette charge, pour laquelle il obtint le concours d'un autre moine de Saint-Cyprien, Bernard, le futur abbé de Tiron ${ }^{137}$. L'abbé de Saint-Savin n'est pas nommé, contrairement à ce que l'on a écrit, comme présent au concile tenu à Poitiers en Io79 sous la présidence d'Hugues de $\mathrm{Die}^{138}$, mais il assista à une décision du duc d'Aquitaine Guy-GeoffroiGuillaume qui mettait en application, pour le chapitre de Saint-Hilaire-le-Grand, le huitième canon de ce concile sur l'interdiction de recevoir dans les ordres sacrés les fils de clercs et les bâtards ${ }^{139}$. Il est encore présent à une assemblée ducale en août $1086^{140}$, et est témoin d'une donation de l'évêque de Poitiers Pierre II à la Chaise-Dieu vers I090141. Vers I09I le pape Urbain II le charge, avec Rainaud, abbé de Saint-Cyprien, de recueillir de l'argent pour l'Église de Rome et d'exiger des monastères soumis à la papauté les cens qu'ils devaient ${ }^{142}$. En I093 l'évêque Pierre II confirme la vingtaine d'églises qui font alors partie du domaine de Saint-Savin ${ }^{143}$. Gervais participe au concile de Clermont en I095 et à celui d'Arles en Iog6. Mais un conflit l'oppose alors à son prieur Bernard à propos d'une église qu'il s'efforce trop " avidement " d'obtenir pour son abbaye. Il échoue d'ailleurs, abandonne alors sa charge, se retire à Saint-Cyprien, puis part pour Jérusalem; il mourra en cours de route, dévoré dit-on par un lion. Les moines de Saint-Savin, appuyés par l'évêque de Poitiers et par l'abbé de Saint-Cyprien, s'efforcèrent, mais en vain, d'obtenir de Bernard qu'il acceptât la succession de l'abbé Gervais, et ils durent choisir un autre abbé ${ }^{144}$. Si pauvres soient-ils, ces renseignements historiques, années troublées entre les abbatiats de deux fortes personnalités au début et à la fin du siècle, n'en ont pas moins l'intérêt de correspondre asse\% exactement à ce que nous apprend la seule étude des inscriptions.

L es dernières inscriptions de la partie orientale de l'église abbatiale sont probablement plus tardives. Dans l'absidiole d'axe du déambulatoire trois personnages sont accompagnés d'inscriptions peintes de chaque côté de leurs têtes. De gauche à droite on lit: ROSA AL . .., HELISABET, ZACHARIAS. I a présence ici des parents de Jean-Baptiste a peut-être quelque rapport avec l'inscription de l'autel consacrée à Hermenegilde qui prit au baptême le nom de Jean. Le premier personnage est sans doute la Vierge, rosa alta (?), le qualificatif de rosa lui étant fréquemment appliqué dans les litanies mariales. Ies éléments paléographiques ne permettent pas de donner une datation plus précise que le $x_{I I}{ }^{e} s$. Au-dessus de ces grands personnages sont représentés en buste huit saints auxquels les anges offrent des couronnes. Huit, c'est le chiffre même des saints porteurs de couronnes dans la partie orientale de la crypte, et c'est aussi le chiffre des saints évêques peints dans le chœur.

Sur le mur oriental de la chapelle voisine, du côté sud, celle dont l'autel est consacré aux saints évêques et aux saints Maixent et Florent, on voyait encore du temps de Mérimée, dans une bande placée sous une figure d'évêque, l'inscription SCS NICHOI,AUS. Mérimée parle d'une facture proche de celle des évêques peints dans le chœur, mais le dessin qu'il en donne montre la présence

137. AA.SS., Avril, II, p. 225

138. Sacrosancta concilia, éd. Ph. LABBE et G. CossART, Paris, t. X, I67I, p. 366-368. A. Richiri), Histoire des comtes de Poiton 778-1204 (Paris, t. I, 1903, p. 339, n. 3), discute de la date attribuée à ce concile, 1078 ou 1079, pour se rallier à cette dernière date; mais faire de l'acte cité dans la note suivante une suite immédiate du concile est forcer le texte, d'autant plus que le légat Hugues de Die qui présida le concile n'y est pas nommé, le légat présent à l'acte étant Amat d'Oloron. Aucun nom d'abbé n'est fourni par le récit du concile.

139. Documents pour l'histoire de l'église de Saint-Hilaire de Poitiers, éd. Reder, Poitiers, i 847 ("Mém. Soc. Antiq. Ouest ", I/14), $n^{\circ} 91$, p. 99.

I 40. Dom Fonteneau, t. XXIV, p. 35.

14. MaRtène et DuRAND, Thesaurus novus anecdotorum, t. I, col. 250.

142. Cartulaire de Saint-Cyprien, éd. REDET, $11^{\circ} 11$, p. 16

I 43. Arch. départ. Vienne, I $\mathrm{H} 7 / \mathrm{I}$.

144. Annales ord. s. Benedicti, V, 1713, p. 378; A.A.S.S., Avril, II, p. 226-227. 
d'un $H$ et d'un $N$ onciaux, ce qui amènerait à proposer une datation plus tardive puisque les inscriptions de la crypte et de la nef ne comportent aucun $H$ ou $N$ oncial.

Enfin au mur nord de l'entrée de la chapelle du croisillon nord du transept une inscription peinte derrière une statue d'ange donne, en lettres qui sont au moins de la fin du $\mathrm{XII}^{\mathrm{e}}$ et même sans doute du XIII $^{\mathrm{e}}$ s., le nom de GABRIEI. La présence dans cette chapelle d'un autel dédié à saint Michel et aux anges peut expliquer ce nom, d'autant plus que Mérimée notait ici en I 845 " quelques restes de peintures représentant des anges ou des saints ${ }^{145}$ \%.

Avec ces diverses inscriptions peintes on reste dans le registre hagiographique qui triomphe dans l'ensemble du chœur, du transept et de la crypte. Il n'en est pas de même avec les deux inscriptions lapidaires qui termineront l'étude épigraphique de cette partie de l'abbatiale. Une pierre funéraire a été réemployée pour former la paroi occidentale du lavabo à l'entrée sud du déambulatoire ${ }^{146}$. L,e texte est très incomplet, mais ce qui en subsiste est fort bien gravé et conservé :

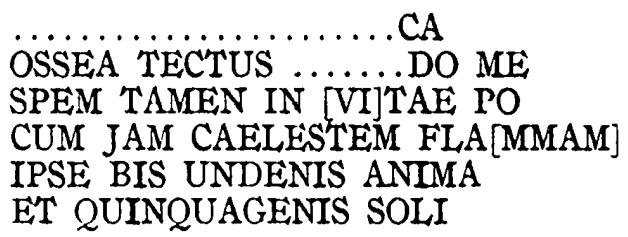

Il s'agit de débuts de vers, très probablement léonins puisqu'on observe régulièrement la coupure après la longue du troisième pied. Le maintien de la diphtongue peut être rapproché de la présence d'une diphtongue dans les inscriptions de la légende de Savin et Cyprien (praeses). Sept $E$ sur douze sont onciaux, un $M$ sur six est également oncial. Le texte peut se situer à la même époque que les inscriptions de la crypte, ou assez peu après.

D'un tout autre intérêt sont les textes gravés sur deux pierres qui, au milieu du siècle dernier, étaient conservées dans la crypte ${ }^{147}$, et qui aujourd'hui sont déposées près des fonts baptismaux. Longuemar, qui est le seul à avoir mentionné ces pierres, y voyait un bas-relief tumulaire. On peut aussi et plutôt penser à un devant d'autel, mais l'état de conservation est médiocre. Il est seulement évident qu'il s'agit d'un même ensemble composé de six compartiments séparés par des moulures qui se terminent en arcs entrecroisés. De gauche à droite on trouve un texte, un personnage tourné vers la droite, un texte, puis à nouveau un texte, un personnage tourné vers la gauche, un texte. A chaque extrémité les textes s'ordonnaient autour d'une croix dont on aperçoit encore nettement la trace. L,e premier texte à partir de la gauche peut être ainsi lu :

\begin{tabular}{ll} 
C & R \\
U & X \\
\multicolumn{1}{c}{ TI } & VE \\
BI PRO & XILL \\
POSIT & UM V \\
A CUN & $\ldots . \mathrm{U}$ \\
C..R & . R \\
UM P & UX ES \\
LENA & T .ER \\
BONO & UM QU \\
RUM & E SIGI
\end{tabular}

I 45. Mérmés, . Votice... (supra, n. 1), p. +2. On ne peut donc penser à une scène de l'Annor.ciation comme il en existe beaucoup à cette époque.

146. Flle est citee par J,oxgrvmak, Eipigraphie... (supra, n. 7), p. 205

17. Ibid., p. 205.206; ne donne le texte que d'une inscription. Cf. figure 7 (première des quatre inscriptions). 
Il s'agit de deux hexamètres, lé second étant sans doute léonin, ce qui permet de proposer la restitution suivante :

\author{
CRUX TIBI PROPOSITA CUNCITOTRUM PLENA BONORUM \\ VEXILAUM VIERUJM CRUA FST [V]ERUMQUE SIGIILLUM. \\ "Ia croix qui t'est proposée est pleine de tous les biens. \\ La croix est le véritable étendard et le vrai sceau. "
}

L,e deuxième texte est trop dégradé pour qu'on puisse y retrourer quelques mots. I,c troisième est le seul qui ne soit pas inédit. Encore ne suivra-t-on pas exactement la lecture qui en a été donnée. Il commence par un hexamètre léonin, se poursuit probablement par un second vers, se termine par une formule de l'épigraphie funéraire:

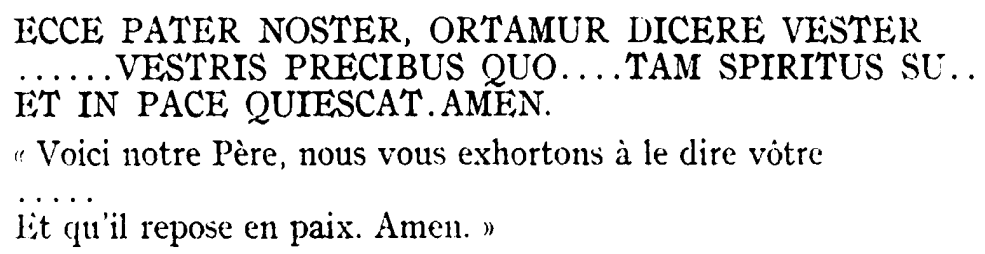

On peut espérer qu'un jour le rapprochement avec telle autre inscription, tel texte littéraire, permettra de restituer la totalité du texte.

La dernière inscription s'ordonne, comme la première, autour d'une croix, soit :

CRUA

FUGAT OM[N]E [M]A[L]UM, CRUX EST REPARACIO RERUM

PER CRUCIS HOC SIGNUM IUUGIT PROCUI, OMNE MALIGNTM.

"Que la croix mette en fuite tout mal, la croix est le renouvellement des choses. Par ce signe de la croix toute malignité s'enfuit. "

Le premier $C r u x$ n'est pas inclus dans la métrique, l'inscription comprenant ensuite un hexamètre léonin à rime simple et un autre, également léonin, à rime riche. Le vocabulaire de cette inscription, ainsi que celui des inscriptions précédentes, se retrouve dans la liturgie relative à la Croix ${ }^{149}$, mais le second vers mérite de retenir un peu plus longucment l'attention, car il montre comment telle ou telle formulation pouvait être employée avec une particulière faveur par l'épigraphiste, sous l'action conjuguée de la poésie et de la liturgie. Il est fréquent que les auteurs empruntent à tel prédécesseur un vers, ou seulement une partie de vers, de telle sorte qu'une recherche de leur emploi dans l'épigraphie devrait amener à étudier non sculement chaque vers, mais chacun de leurs éléments. Raban Maur commence un de ses vers par : $P_{c r}$ crucis hoc signum ${ }^{149}$, et l'on trouve presque exactement la fin du vers employé à Saint-Savin chez Hildebert de Lavardin ${ }^{150}$ et surtout Renier de Liège ${ }^{151}$. L'expression est retenue par la liturgie et le vers inscrit à Saint-Sarin apparait

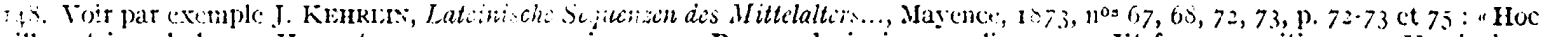

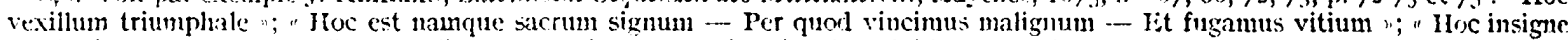
crucis sigmm ... Ilostem cfifugat malignum "; "Sighum est victoriac, hoc sigillum suumi regis..., hoc vexillum gloriac. : Le terme de sisnum, herite de Constantin, se trouve dans plusieurs inscriptions de l'Afrique chretienne (Inscriptioncs .1 fricai latinac, éd. C. Wry.

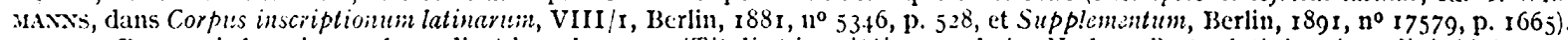
1.9. "Per crucis hoc signum hanc dicet ipse domum "(Tituli et inscriptiones ecclesiac $\$$, dans Poetae latini aevi carolini, ed. Drin. inj:!: t. II, R. 223 .

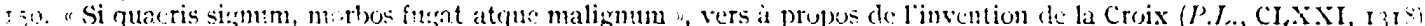

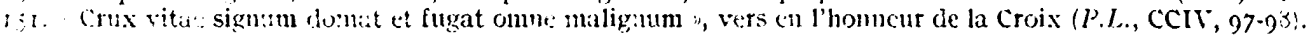


tel quel dans une antiemne de la Croix ${ }^{152}$. Elle passe dans les recueils de formules et se trouve dans deux mss. de Vienne et un de Paris aux $x \mathrm{~V}^{\mathrm{e}}$ et $\mathrm{xV} v^{\mathrm{e}} \mathrm{s} .{ }^{153}$. L'épigraphiste a pris son texte dans l'une ou l'autre de ces sources, et probablement dans la liturgie. Ce même texte se retrouve sur un tau du musée de Cluny du $\mathrm{xII}^{\mathrm{e}}$ ou du XIV $\mathrm{s}$. pour accompagner la consécration de l'évêque par le pape : Lex Dei zera est. Per crucis hoc signum fugiat malignum ${ }^{154}$, et sur une cloche du XIII ${ }^{\mathrm{e}} \mathrm{s}$. provenant de l'ancien prieuré de Degagnazès et conservée à Peyrilles dans le Lot ${ }^{155}$. L'analyse paléographique conduit à attribuer à ces quatre dernières inscriptions de Saint-Savin une date nettement plus tardive que celle des inscriptions peintes. La progression des onciales notamment est sensible, quatorze $E$ sur vingt-trois, quatorze $M$ sur quinze, trois $N$ sur cinq. Il n'y a pas encore du moins une prépondérance totale de l'onciale, car on n'a ni $H$ ni $U$ oncial, et le $T$ oncial n'est représenté, semble-t-il, que par une lettre. Ces textes sont probablement du xir ${ }^{\mathrm{e}} \mathrm{s}$.

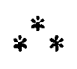

Les inscriptions ont tenu un róle majeur dans l'histoire de l'Ancien Testament peinte dans la nef de l'église abbatiale de Saint-savin. Ein effet elles figuraient dans le champ des scènes pour identifier les personnages, dans les bandes qui séparent les registres pour commenter les scènes, sur les tables de la I,oi et sur les phylactères des prophètes pour transmettre paroles et citations. Malheureusement la quasi-totalité des textes a disparu, et l'épigraphiste ne peut ici apporter qu'une aide limitée à l'historien de l'art.

Dans le champ même le peintre s'est borné à inscrire les noms des personnages représentés, mais il ne l'a pas fait de façon systématique. Abel et Caïn sont accompagnés de leurs noms dans la scène où ils présentent leurs offrandes à Dieu; le nom de Noë est répété quatre fois, et dans la scène de l'ivresse sont identifiés Cham et, semble-t-il, Sem; le nom de Joseph est aussi peint à quatre reprises, et celui du pharaon l'est dans la scène où Joseph reçoit l'anneau; enfin lorsque l'artiste a représenté Dieu apparaissant à Abraham, il a jugé bon de peindre I $\bar{H} S$ XPS. I,es noms sont généralement placés au-dessus des têtes, mais on a, en fait, utilisé la place laissée disponible par la représentation des scènes, et certains noms sont inscrits de chaque côté de la tête (le Christ-Dieu), verticalement (Cham), en oblique (Noë). C'est dire que ces inscriptions d'identification étaient placées en dernier lieu, et il conviendrait de préciser la période chronologique pendant laquelle on a ainsi identifié systématiquement ou presque les personnages, même dans les cas où l'iconographic parlait d'ellemème, car il est certain qu'elles deviendront moins fréquentes au fur et à mesure que l'iconographie se précisera, et sans doute aussi que cette habitude cessera d'être en faveur. On notera que l'écriture y est plus spontanée, moins soignée, que celle que l'on trouve dans les textes de la bande médiane, comme il est net en particulier avec le nom de Joseph ( $O$ en navette, écartement irrégulier des lettres), reproduit en figure iI.

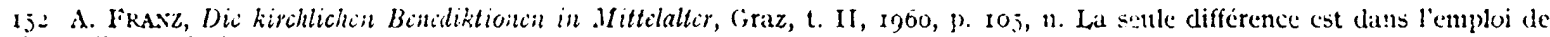
fugiat au lieu de fugit.

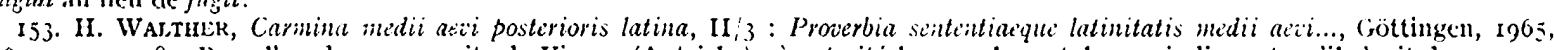
$1^{\circ} 2$ I 192, p. 780. Pour l'un des manuecrits de V'ienne (Autriche) où est cite le vers, les catalogues indiquent qu'il s'agit de " poema rersibus koninis concinnatum, sententias argumenti ethici complectens ". Pour le manuscrit de Paris (B..., lat. 8247 , fol. I 3 I), le vers de Sinint-Savin est compris dans des épigrammes, centons, vers mucmotechniques et citations diverses "; on notera gute seul a eté retenu le premier des deux vers a rimes riches consiacres a la Croix: "Per crucis hoc signum fugiat procul omme malignum .. lit per idem tempus salvetur quodque betignum ", et que ce texte est suivi notamment de deux vers employés dans l'épigraphite campa. naire: "I audo I) eum verum, plebem viso, congrego clerum -- Deffunctos ploro, pistes fugo, festal decoro."

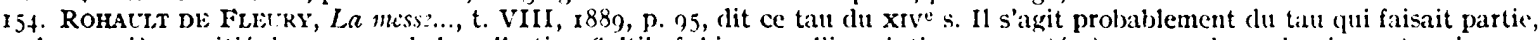
dans la premiere moitie du xIx" s., de la collection Soltikof, bien que l'inseription rapporté a propos de ce dernice se termine par "fugiat omne malignum ", ef que le tan soit claté du xinc s.

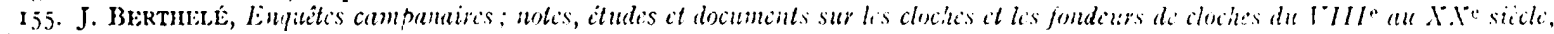
Montpellier, 190,5 , p. 525 . 
Une bande faîtière refaite sépare les scènes du côté nord de celles du côté sud, et une bande de couleur sombre partage chaque côté de la voûte en deux registres. Des textes ont été peints, en lettres blanches, dans la totalité de cette dernière bande, et on peut encore, ici et là, en relever quelqu es lettres, voire quelques mots. Ėn dehors de leur évidente utilité pour une étude de l'écriture ces fragments permettent trois observations. En premier lieu il est certain qu'ils s'appliquent aux scènes du registre inférieur. I,es mots mare ou persequentes s'appliquent au passage de la mer Rouge et no n au meurtre d'Abel et à l'assomption d'Enoch, le nom de Moïse ne peut s'appliquer à l'histoire de Noë peinte au registre supérieur, fratres et anulıs renvoient à l'histoire de Joseph, Isaac Jacob benedixit et corpus Abraham concernent évidemment la bénédiction de Jacob par Isaac, la sépulture d'Abraham. Un mot partiel pourrait amener à une hésitation, celui d'erba, car on pourrait penser à gerba, c'est-à-dire à l'offrande de Caïn au registre supérieur, le mot de garba figurant pour la même scène sur un chapiteau du cloître de Moissac; mais on peut considérer aussi qu'il s'agit du mot verba, c'est-à-dire du discours de Dieu à Moïse au registre inférieur. Du même coup on est conduit à se demander s'il n'y a pas eu, à l'origine, en place de la bande faîtière, deux bandes qui auraient comporté les textes relatifs aux scènes des registres supérieurs ${ }^{156}$. Deuxième observation : il s'agit d'une identification des scènes à partir de l'Écriture, non pas avec une exactitude qui aboutirait à des citations, mais d'assez près pour emprunter ici et là les mots mêmes de la Genèse : benedixit, fratres, amulus, ou de l'Exode, persequentes, filii Israël. Cette fonction d'identification est loin d'être inutile puisqu'on a longtemps mal interprété la bénédiction de Jacob par Isaac ${ }^{157}$. Mais il n'est sûrement pas question ici d'inscriptions qui viseraient à tirer des scènes représentées quelque leçon morale ou quelque commentaire général. Pourtant, et c'est la troisième observation, on peut se demander s'il ne s'agit pas de vers. La métrique qu'exige l'hexamètre, le vers médiéval par excellence, est observée dans dum caruit, et Dominus mare, inimici fratres, Isaac Jacob benedixit, et surtout dans ce qui correspond à un vers complet si on admet une synérèse - union de deux voyelles qui se suivent - dans la finale du mot Israel : Et salvavit Moïsen et filios Israel ${ }^{158}$. Mais les quantités ne sont pas observées dans persequentes, insignitus anulus, corpus Abraham, et il serait abusif de voir partout des licences poétiques. Il ne peut, de toute façon, s'agir ici de vers léonins. Peut-être a-t-on simplement approché souvent la forme versifiée en cherchant des formules ramassées, donc faciles à retenir, pour identifier les scènes. Même si les textes qui subsistent sont trop partiels pour autoriser des affirmations catégoriques, il fallait au moins poser la question pour pouvoir permettre le plus complètement possible la comparaison entre les inscriptions de la nef et celles des autres parties de l'édifice.

On ne trouve que dans la nef l'emploi d'un "livre " ou d'un phylactère comme support d'une inscription. Lorsque, au registre inférieur du côté nord de la voûte, l'artiste a représenté la remise des tables de la I,oi à Moïse, il a inscrit sur les tables deux des commandements : DEUM ADORA à gauche, NON OCCIDES à droite. Le premier présente, sous la forme la plus brève possible, la prescription des versets 3-7 du chapitre XX de l'Exode, le second cite exactement le verset I3 du même chapitre. Dans le livre du Deutéronome, après la répétition du Décalogue, Moïse recommande à Israël de conserver avec soin ces commandements et de les écrire sur le seuil et les portes des maisons: Scribes ea in limine et ostiis domus tuae ${ }^{159}$. La prescription de Moïse a été suivie à la lettre après la captivité, lorsque se développa le pharisaïsme. Pourtant l'épigraphiste

156. Au cours de la récente campagne de restauration Mme AI.-Fr. de Christen aurait rencontré, sous cette bande faitière, au nivcau de la vic d'Abraham, une lettre $A$.

157. La même scène, avec une inscription analogue : HIC BEATDIXIT YSAAC JACOB FILIUM SUCN, se trouve à la cathédrale de Monreale et a la chapelle palatine de Palerme (O. Desirs, The Mosaics of Yorman Sicily', Irondres, 1950, p. 107 et $35^{\mathrm{B})}$.

158. On peut lire avec certitude : I'T SAI, YAVIT IIOISSEN FiT, puis avec probabilité : FILIOS, et enfin les lettres $S$ et $A$ avec l'espacement correspondant au mot Israël.

15\%. DT., VI, 9; cf. aussi XI, 20 : "Scribes ca super postes et januas domus tuae. a Reprorluction des tables de la Ioi, figure 10. 
médiéval n'a que rarement fait sienne cette prescription, car il n'a guère utilisé le Décalogue, si ce n'est au portail central de la façade occidentale de la cathédrale de Borgo San Donnino [Fidenza] où des persomnages portent inscrits sur des banderoles non seulement le DILIGES DOMINUM et le NON OCCIDES de Saint-Savin, mais encore les $2^{\mathrm{e}}, 6^{\mathrm{e}}, 7^{\mathrm{e}}$ et $9^{\mathrm{e}}$ commandements ${ }^{160}$, et à Compostelle où Moïse tient les tables de la I,oi sur lesquelles on lit : HONORA ${ }^{161}$.

Les phylactères servirent très fréquemment, dans la maniature, la peinture, la sculpture, aux citations de l'Ancien T'estament et spécialement à celles tirées des livres des prophètes. A Saint-Savin dans les écoinçons des cinq dernières colonnes de la nef ont été peints dix prophètes de grande taille. Les phylactères qu'ils tiennent en leurs mains ont de 90 à I Io cm de haut et les textes devaient aisément être lus d'en bas en dépit de la hauteur de la nef. Malheureusement on ne distingue plus aujourd'hui, même à un examen rendu exceptionnellement aisé par la présence d'échafaudages au moment des travaux de restauration, que quelques lettres. L,e texte tenu par le deuxième prophète à partir de l'ouest, du côté nord, est le mieux conservé, et il était déjà mentionné partiellement par Mérimée ${ }^{162}$. Il s'agit de : SICU'T FUIT JONAS IN VENTRE, ce qui identifie le prophète, mais à partir d'une citation de l'évangéliste Matthieu ${ }^{163}$. Quant au prophète suivant, le troisième à partir de l'ouest du même cóté, le mot SION et la présence de deux lì et d'un X permettent de l'identifier avec Zacharie. Compte tenu de la place disponible et de la disposition des lettres qui subsistent, le texte de Zacharie : Exulta satis filia Sion; jubila, filia Jerusalem, ecce rex tuus veniel (IX, 9) est probablement cité d'après Matthieu (XXI, 5) : Dicite filiae Sion, ecce rex utus venit. L'inscription devait etre : [DICITE IIILIAE] SION E[CC]E [RE]X.

I.e texte de Matthieu mentionnant Jonas comme une figure de la Résurrection était lu à l'évangile du mercredi des Quatre-Temps en Carême, celui qui cite Zacharie servait d'évangile lors de la bénédiction des Rameaux. I, Guide de la peinture, publié au siècle dernier par Didron, recommandait d'ailleurs d'utiliser ce texte de Zacharie pour les représentations de la fête des Rameaux ${ }^{164}$, et ce même texte était inscrit sur le phylactère de Zacharie en tête de son livre dans la Bible de Souvigny ${ }^{165}$. Une étude récente a montré que "ce sont tous les textes lus ou chantés ici, de la Septuagésime à Pâques, qui forment le fort tissu du programme pictural " de la nef ${ }^{166}$. Après le cycle hagiographique de la partie orientale de l'édifice, le cycle de l'Ancien T'estament de l'ensemble de la nef s'inscrit donc dans une même corrélation étroite avec la liturgie.

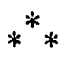

Cycle de la Passion et cycle hagiographique se combinent à la tribune, très probablement pour des raisons liturgiques auxquelles il conviendrait de consacrer l'étude qu'elles méritent. I a description très précise du cycle de la Passion a été donnée par Mme Y. I,abande-Mailfert, qui a souligné à fort juste titre combien il serait vain d'y chercher une "succession rigoureusement exacte des faits ${ }^{167}$ ". Passion et Résurrection occupent presque entièrement la partie orientale de la tribune.

160. A. Kingsley Pokтек, Lombard Architecturi, New Haven $/ 1$ ondres/Oxford, ig 6, t. II, p. Is I.

16r. (G. CinithaRd, Le Porche de Gloire à Saint-Jacque's-de-Compostelle et ses origine's espagnoles, "Cahiers civil. mediév. , I, 1958, p. 468 .

162. Mérmée, Notice..., p. 4 I et fig. I6.

163. MT, XII, to: "Sicut enim fuit Jonas in ventre ceti tribus diebus et tribus noctibus.

I64. Mantel d'iconographie chróticnth: grecque ct latinc avec introd. et notes par M. DIDRos, trad. du manuscrit byzantin Le guide de la peinture, par P. Dekasd, Paris, $15.5,1$. I.p.

165. Bibl. mun. Moulins, ms. I, fol. $200 \mathrm{v}^{0}$. Le texte de Zacharie se trouve aussi au portail de la cathedrale de Vérone (PortEre, op. cit., t. III, p. 476-477), dans la chapelle de San Pellegrino dans les Abruzzes (Í. BERTat:x, L'art dans l'ltalic méridionale, t. I, I904, p. 290-292), à la Martorana à Palerme (Dexts, op. cit., p. 87-88).

166. Y. LABA.NDE-MAILFEkT, Le cycle de l'Ancien Testament à Saint-Savin, "Rev. d'hist. spiritualité ", I, 1974, p. 392-393. On trouvera aussi un commentaire de ces scenes dans R. OT:RSEL, La Bible de Saint-Savin, La Pierre-qui-vire, I97 (" Points cardinaux", 20).

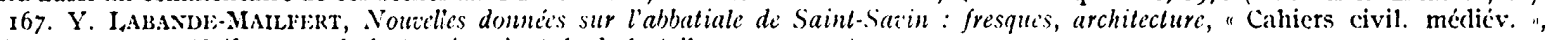
XIV, I9) 1, p. 39.68 (fresques de la travéc orientale de la tribunc, p. $4 \mathrm{I}-58$ ). 
Au-dessus des scènes qui forment le centre même de la composition - de bas en haut la Descente de croix, la Main de Dieu, l'Agneau, - est représenté le Christ entouré de deux saints, en lesquels il faut peut-être voir saint Pierre et saint Paul, puisque, en I934/35, 1'artiste chargé du relevé de ces fresques a vu, à la hauteur des épaules du saint placé à la droite du Christ, en blanc sur fond vert, \$ $\mathrm{P}$ (ou F ?) $)^{168}$. A la hauteur de cette scène, sur le départ de la voûte au nord, était peint un saint qu'une inscription relevée également en I935 identifie vraisemblablement à saint Savin (de chaque côté de la tête : ..ABI NUS) ${ }^{169}$. Les scènes de la Passion, au mur nord Baiser de Judas et Flagellation, au mur sud Déploration et Mise au tombeau, sont comprises entre, à la partie supérieure, six apôtres sous des arcatures, à la partie inférieure, le Martyre de saint Denis, évêque de Paris, au mur nord, le Baptême de saint Denis l'Aréopagite par saint Paul au mur sud; les deux saints Denis étant confondus au $\mathrm{XI}^{\mathrm{e}} \mathrm{s}$. Il y a quarante ans on lisait encore : DIONISIUS ${ }^{170}$ au-dessus du saint décapité et à gauche de la tête que Denis tenait entre ses mains; PAULUS ${ }^{171}$ à la droite de Paul au mur sud, à la hauteur du nimbe. La partie occidentale des murs nord et sud était occupée par d'immenses portraits de saints, superposés sur quatre registres jusqu'à la voûte. A la hauteur du baptême de saint Denis était peint saint Gelais, le troisième successeur de saint Hilaire sur le siège de Poitiers, identifié par son nom inscrit de chaque côté de sa tête: GEL A... ${ }^{172}$, et Mérimée rapporte (en 1845) : "On distinguait encore il y a quelques années le nom de saint Fortunat, un des plus célèbres évêques de Poitiers ${ }^{173}$ ". Ainsi retrouve-t-on à la tribune une pensée analogue à celle qui a inspiré le programme du chœur - les huit figures d'évêques dont celle de Fortunat et de la crypte. Pour expliquer la composition des peintures de la tribune il conviendrait de ne pas dissocier le cycle de la Passion et de la Résurrection du cycle hagiographique qui y tient une place très importante, comme l'a souligné le professeur I. Yoshikawa dans une récente étude sur Saint Denys à Saint-Savin, et de tenir compte des peintures aujourd'hui presque totalement disparues du mur ouest - le Tétramorphe et les douze apôtres - discernées et évoquées par le même auteur ${ }^{174}$.

Quant à l'épigraphie, elle est ici conforme à ce que l'on pouvait observer dans la nef. Les différentes scènes, les personnages sont identifiés par des inscriptions dans le champ, peintes en dernier en fonction de la place disponible. C'est ainsi que dans la Déposition de croix, scène centrale de la composition, le nom de la Vierge, [M]ARIA, a pu être placé à gauche (pour le spectateur) du nimbe, tandis que celui de Nicodème a dû être tracé le long du manteau du personnage, en plusieurs lignes:

$$
\begin{aligned}
& \mathrm{NI}[\mathrm{CO}] \\
& \mathrm{D} \\
& \mathrm{E} \\
& \mathrm{M}[\mathrm{US}]
\end{aligned}
$$

De même le mot CEN'TURIO au mur nord est écrit sur deux lignes, la seconde ne comportant que la lettre $O$. Dans la scène du Baiser de Judas les lettres $\widehat{\mathrm{I}}(\mathrm{S})$ étaient tracées à gauche (pour le spectateur) du nimbe crucifère du Christ ${ }^{175}$, et au-dessus du tombeau vide on lit : SEPULCRO

168. Muscé des Monuments français, M.H. 16771. Je remercie très vivement ici le conservateur en chef du Musée, M. Marc Thibout, qui a bien voulu me faciliter, dans les meilleures conditions, l'étude des relevés exécutés par Jacques Socard en I $934 / 35$ à Saint-Savin. 169. Ibid., M.II. 16773. I' aquarelle a été publiée par A. GRABAR, L'étude des fresques romanes, "Cahiers archéol. ”, II, 1947, p. 170, pl. 28.

170. Musée des Monuments français, M.H. 26777.

17r. Ibid., M.H. I6778.

172. Ibid., M.H. 16774 .

173. MÉrImÉ, Notice..., p. 47

174. I. Yosmikawa, Saint Denys à Saint-Savin, ćtude publiée en japonais en 1973, avec résumé français.

175. Musće des Monuments français, M.H. 16776 . 
$\widetilde{\mathrm{DN}}$, ablatif qui semble avoir été précédé de une ou deux lettres ${ }^{176}$. Un mot a également été inscrit dans la scène de la Mise au tombeau entre les anges qui encensent le corps du Christ ${ }^{17}$, et nous avons déjà cité les noms qui identifiaient les saints représentés dans le reste de la tribune. On peut penser que le programme général n'a pas prévu avec précision ces inscriptions, mais que celles-ci ne sont intervenues qu'après coup, selon les habitudes de l'époque, pour mieux guider le spectateur. On ignore si quelque texte a été inscrit sur le phylactère que Paul tient dans sa main gauche dans la scène du Baptême de Denis, à l'image de ce qui a été réalisé pour le Baptême du centurion Corneille par saint Pierre dans les célèbres fonts baptismaux de Saint-Barthélemy de Liège. Mais il faut noter qu'un long texte a été peint dans la bande rouge qui souligne la partie inférieure des scènes tant au mur nord qu'au mur sud, et ce, y compris sur les ressauts des piliers de la partie orientale de la tribune. Il doit en fait s'agir de deux textes, car celui du mur sud commence par une croix. Au mur nord on lit encore, sous le Martyre de Denis, PRID..., et sous l'Apparition du Christ aux disciples d'Emmaüs le mot X̂XICOLIS, tandis qu'au mur sud, sous l'Apparition à Marie-Madeleine on peut déchiffrer quelques lettres sans en saisir la signification :

$$
+ \text {.RI. } \widehat{A} \text { STCVNCTACOG/AGIS/.../FIA/ }
$$

Les formes des lettres sont très comparables à celles que l'on observe dans la crypte et dans la nef, écriture arrondie et régulière, sans signes de ponctuation; les abréviations, très classiques, $\widehat{\mathrm{IHS}}$ $\widehat{\mathrm{DNI}}, \widehat{\mathrm{XPI}}$ sont indiquées avec le tilde à léger renflement médian généralement employé à la fin du XI ${ }^{\mathrm{e}}$ et au XII ${ }^{\mathrm{e}}{ }^{178}$, qui accompagne aussi le nom de saint Savin dans la partie orientale de la crypte; le $M$ oncial de Nicodemus est tout à fait comparable à celui de Maximus dans la crypte, et on trouve aussi dans la bande inférieure un $D$ oncial analogue à ceux de la crypte et de la nef.

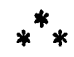

Comme dans la tribune les inscriptions du narthex ont souffert au point qu'elles sont pratiquement inutilisables aujourd'hui. Pourtant, comme dans tout le reste de l'abbatiale, les scènes qui y sont peintes, consacrées à l'Apocalypse, étaient accompagnées d'inscriptions, tracées dans les bandes qui séparent les différents registres. Ces textes semblent, comme dans la crypte, se rapporter aux scènes qui sont placées au-dessus d'eux, si l'on en juge par les lettres ...S EJUS AD EUM RAPITUR, qu'on peut sans doute rapprocher d'un passage de l'Apocalypse, et raptus est filius ejus ad Deum (XII, 5), relatif à la lutte entre la femme et le dragon. On distingue aussi un ANG(ELI) qui doit s'appliquer au combat entre Michel et ses anges et le dragon. De chaque côté du Christ en majesté qui occupe le tympan de l'arc oriental on peut encore lire l'alpha et l'omega suspendus par de petites chaînes, selon une formule très fréquente notamment en Espagne. Il s'agit d'une illustration de la citation bien connue : Ego sum alpha et omega, principium et finis (Ap. I, 8). De la forme arrondie et régulière des lettres, de la présence d'un $D$ oncial, on ne peut tirer de conclusion bien étayée, en raison du trop petit nombre de lettres encore visibles.

Au terme de cette étude du dossier épigraphique de Saint-Savin on se gardera de toute façon de conclusions catégoriques. L'épigraphie ne peut suppléer à l'histoire de l'art, même si elle est

376. Ibid., M.H. 16234. Peut-être s'agit-il de a, de, ou ex sepulcro Domini. Cf. MT, XXVIII, 8, de monumento; LC, XXIV, 2, a monumento; JN, $\mathrm{XX}, \mathrm{I}$, vidit lapidem sublatum a monumento.

177. Musée des Monuments français, M.H. 16775

78. Ce tilde est représenté quatre fois à la tribune (la quatrième fois dans la bande sous l'Apparition à Madeleine). Dans la crypte ct dans la nef le tilde est droit. 
susceptible de lui apporter une utile contribution. De plus il faudra encore un certain nombre d'années avant que les différents champs de recherche propres à l'épigraphie soient suffisamment explorés, et les travaux qui se poursuivront encore dans l'abbatiale ainsi que les progrès techniques permettront sans doute d'aller un peu plus loin dans le déchiffrement des inscriptions. A moins que l'usure du temps ne continue, inexorablement, à faire son œuvre...

Il me semble toutefois qu'on peut au moins, en reprenant certaines indications déjà données, présenter plusieurs observations générales :

Io L'étude des inscriptions de Saint-Savin oblige à considérer qu'il y a une distance très nette entre les inscriptions gravées sur les autels et celles qui accompagnent les peintures murales. D'une part on trouve irrégularité, abondance des conjonctions, enclavements, entrelacements, ponctuation assez désordonnée, prédominance des formes carrées, rareté des onciales; d'autre part on a régularité, absence de conjonctions, enclavements et entrelacements, absence aussi, autant qu'on puisse en juger, de ponctuation, avec seulement à deux reprises séparation de phrases par des croix dans la nef et dans la tribune, disparition totale des formes carrées remplacées partout par de belles formes arrondies, progression très sensible des onciales, à l'exclusion toutefois des $H, \operatorname{des} N$, des $T$ et $\operatorname{des} U$. A défaut de pouvoir encore s'appuyer sur un fichier général des formes paléographiques, qui est du moins achevé pour le nord de l'Aquitaine, on peut dire que toutes les comparaisons effectuées avec les inscriptions datées incitent à penser que les inscriptions des autels de Saint-Savin ne sont pas postérieures au milieu du $\mathrm{XI}^{\mathrm{e}} \mathrm{s}$., alors que les inscriptions peintes se placeraient plutôt à la fin du même siècle ou au début du suivant. On observera que l'abbaye de Saint-Savin a connu au $\mathrm{XI}^{\mathrm{e}} \mathbf{s}$. deux abbatiats importants, celui d'Odon, de roro à I040 environ, celui de Gervais, de I079/80 à 1096 environ.

$2^{\circ}$ Les inscriptions peintes ont été étudiées d'est en ouest sans le moindre souci de prendre parti dans les discussions des archéologues sur les différentes étapes de la construction, ni des historiens de l'art sur la date ou les dates des peintures murales. Au point de vue de l'épigraphie il faut conclure qu'il y a une large homogénéité d'ensemble entre les écritures des inscriptions de la crypte, du chœur, de la nef, de la tribune, du narthex. C'était déjà la conclusion de Paul Deschamps en I95I, au terme d'un examen qui ne prétendait pas à la relative exhaustivité à laquelle nous nous sommes ici attaché ${ }^{179}$. Les éléments ont été fournis, chemin faisant, qui pourraient permettre de distinguer plusieurs mains. Mais les inscriptions autres que celles de la crypte sont trop dégradées pour que l'on puisse proposer avec assez d'arguments une répartition de la tâche entre plusieurs scribes.

$3^{\circ}$ Comme il a déjà été indiqué, il y a une correspondance exacte entre les inscriptions des autels et le programme de la crypte. L'essor des constructions romanes au $\mathrm{XI}^{\mathrm{e}} \mathrm{s}$. ne doit pas être séparé du culte des saints à cette époque, mais il nous manque un ouvrage de base sur cet aspect fondamental de la spiritualité et des mentalités du temps. On ne saurait trop insister sur les raisons fonctionnelles qui conduisaient le maître d'œuvre dans la construction d'un édifice religieux, donc sur les liens étroits entre architecture et liturgie, épigraphie et liturgie.

$4^{\circ}$ Les inscriptions sont faites pour être lues du plus large public. En raison de ce caractère fondamental on peut dire qu'elles reflètent assez exactement un niveau de culture. Culture encore très simple au niveau des inscriptions des autels, avec notamment une ignorance assez étonnante des genres et des déclinaisons. L'emploi de verbes précieux, combiné avec une mauvaise connaissance des constructions qu'ils devraient commander, paraît quelque peu artificiel, tout comme la présence

179. P. Deschasups, Peintures de Saint-Sazin, dans Congrés archéol., Poitiers, 1951, p. 447-448; P. Deschamps et M. Thibolt, La peinture muralc in France; le haut moyen $a_{y}{ }^{\prime}$,..., p. $78 \cdot 79$ et 85 . 
d'un vers introduit maladroitement au milieu de l'inscription de l'absidiole d'axe du déambulatoire. Les inscriptions peintes témoignent, au contraire, d'une bonne "latinité ", voire même d'une certaine recherche, avec la construction de plusieurs hexamètres léonins. Faut-il y voir une influence de l'abbé Gervais et de son prieur Bernard, tous deux formés en l'abbaye de Saint-Cyprien de Poitiers, où il a peut-être existé, à côté des écoles sûrement attestées et importantes de la cathédrale et de Saint-Hilaire-le-Grand, une école monastique? On ne peut du moins parler de textes savants à la manière des inscriptions mosanes ou rhénanes de l'époque. Bien plutôt il s'agit simplement d'accompagner l'image, comme il est habituel à l'époque, et comme on le trouve alors, par exemple, au tympan du portail de Conques ou sur les chapiteaux du cloître de Moissac. L'église de Saint-Savin, qui nous émerveille par l'importance de sa décoration picturale, nous laisse également deviner ce qu'a pu être le développement des inscriptions dans les différentes parties d'un édifice religieux de l'époque. Et l'épigraphie, carrefour de diverses disciplines, paléographie, hagiographie, liturgie, linguistique, poésie, etc., nous invite à dépasser l'horizon familier de nos propres spécialités pour mieux saisir la complexité et l'originalité de la culture médiévale ${ }^{180}$.

180. Le relevé aussi complet que possible des inscriptions de Saint-Savin, avec les mesures et localisations précises, est donné daus le deuxième fascicule du Corpus des inscriptions de la France médiévale, Poitiers, I976. Ce m'est l'occasion de remercier ici mon ami Jean Michaud pour l'aide qu'il m'a apportée dans la préparation de cet article. 